\title{
RESEARCH
}

Open Access

\section{The plasma peptides of Alzheimer's disease}

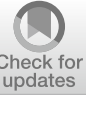

Angelique Florentinus-Mefailoski ${ }^{1}$, Peter Bowden' ${ }^{1}$, Philip Scheltens ${ }^{2}$, Joep Killestein ${ }^{3}$, Charlotte Teunissen ${ }^{4}$ and John G. Marshall ${ }^{1,5^{*}}$ (D)

\begin{abstract}
Background: A practical strategy to discover proteins specific to Alzheimer's dementia (AD) may be to compare the plasma peptides and proteins from patients with dementia to normal controls and patients with neurological conditions like multiple sclerosis or other diseases. The aim was a proof of principle for a method to discover proteins and/ or peptides of plasma that show greater observation frequency and/or precursor intensity in AD. The endogenous tryptic peptides of Alzheimer's were compared to normals, multiple sclerosis, ovarian cancer, breast cancer, female normal, sepsis, ICU Control, heart attack, along with their institution-matched controls, and normal samples collected directly onto ice.
\end{abstract}

Methods: Endogenous tryptic peptides were extracted from blinded, individual AD and control EDTA plasma samples in a step gradient of acetonitrile for random and independent sampling by LC-ESI-MS/MS with a set of robust and sensitive linear quadrupole ion traps. The MS/MS spectra were fit to fully tryptic peptides within proteins identified using the X!TANDEM algorithm. Observation frequency of the identified proteins was counted using SEQUEST algorithm. The proteins with apparently increased observation frequency in AD versus AD Control were revealed graphically and subsequently tested by Chi Square analysis. The proteins specific to AD plasma by Chi Square with FDR correction were analyzed by the STRING algorithm. The average protein or peptide $\log _{10}$ precursor intensity was compared across disease and control treatments by ANOVA in the R statistical system.

Results: Peptides and/or phosphopeptides of common plasma proteins such as complement C2, C7, and C1 QBP among others showed increased observation frequency by Chi Square and/or precursor intensity in AD. Cellular gene symbols with large Chi Square values $(X 2 \geq 25, p \leq 0.001)$ from tryptic peptides included KIF12, DISC1, OR8B12, ZC3H12A, TNF, TBC1D8B, GALNT3, EME2, CD1B, BAG1, CPSF2, MMP15, DNAJC2, PHACTR4, OR8B3, GCK, EXOSC7, HMGA1 and NT5C3A among others. Similarly, increased frequency of tryptic phosphopeptides were observed from MOK, SMIM19, NXNL1, SLC24A2, Nbla10317, AHRR, C10orf90, MAEA, SRSF8, TBATA, TNIK, UBE2G1, PDE4C, PCGF2, KIR3DP1, TJP2, CPNE8, and NGF amongst others. STRING analysis showed an increase in cytoplasmic proteins and proteins associated with alternate splicing, exocytosis of luminal proteins, and proteins involved in the regulation of the cell cycle, mitochondrial functions or metabolism and apoptosis. Increases in mean precursor intensity of peptides from common plasma proteins such as DISC1, EXOSC5, UBE2G1, SMIM19, NXNL1, PANO, EIF4G1, KIR3DP1, MED25, MGRN1, OR8B3, MGC24039, POLR1A, SYTL4, RNF111, IREB2, ANKMY2, SGKL, SLC25A5, CHMP3 among others were associated with AD. Tryptic peptides from the highly conserved C-terminus of DISC1 within the sequence MPGGGPQGAPAAAGGGGVSHRAGSRDCLPPAACFR and ARQCGLDSR showed a higher frequency and highest intensity in AD compared to all other disease and controls.

\footnotetext{
${ }^{*}$ Correspondence: 4marshal@ryerson.ca

${ }^{1}$ Ryerson Analytical Biochemistry Laboratory (RABL), Department

of Chemistry and Biology, Faculty of Science, Ryerson University, 350

Victoria St., Toronto, ON, Canada

Full list of author information is available at the end of the article
}

(C) The Author(s) 2021. This article is licensed under a Creative Commons Attribution 4.0 International License, which permits use, sharing, adaptation, distribution and reproduction in any medium or format, as long as you give appropriate credit to the original author(s) and the source, provide a link to the Creative Commons licence, and indicate if changes were made. The images or other third party material in this article are included in the article's Creative Commons licence, unless indicated otherwise in a credit line to the material. If material is not included in the article's Creative Commons licence and your intended use is not permitted by statutory regulation or exceeds the permitted use, you will need to obtain permission directly from the copyright holder. To view a copy of this licence, visit http://creativeco mmons.org/licenses/by/4.0/. The Creative Commons Public Domain Dedication waiver (http://creativecommons.org/publicdomain/ zero/1.0/) applies to the data made available in this article, unless otherwise stated in a credit line to the data. 
Conclusion: Proteins apparently expressed in the brain that were directly related to Alzheimer's including Nerve Growth Factor (NFG), Sphingomyelin Phosphodiesterase, Disrupted in Schizophrenia 1 (DISC1), the cell death regulator retinitis pigmentosa (NXNI1) that governs the loss of nerve cells in the retina and the cell death regulator ZC $3 \mathrm{H} 12 \mathrm{~A}$ showed much higher observation frequency in AD plasma vs the matched control. There was a striking agreement between the proteins known to be mutated or dis-regulated in the brains of AD patients with the proteins observed in the plasma of AD patients from endogenous peptides including NBN, BAG1, NOX1, PDCD5, SGK3, UBE2G1, SMPD3 neuronal proteins associated with synapse function such as KSYTL4, VTI1B and brain specific proteins such as TBATA.

Keywords: Alzheimer's, Plasma, Peptides, Peptidome, Mass spectrometry, Organic extraction, C18, Alzheimer's dementia, Human EDTA plasma, Nano chromatography, Electrospray ionization tandem mass spectrometry, LC-ESIMS/MS, Linear quadrupole ion trap, Discovery of variation, Random and independent sampling, Chi square test and ANOVA, SQL SERVER \& R

\section{Introduction}

Studies of Alzheimer's Dementia (AD) seem to show that proteins from the brain may be circulating in the blood [1]. AD may be associated with aberrant gene expression and RNA metabolism [2,3], accompanied by cell death and clearance of cells from the brain [4]. There have been many proteomic studies to date focused on finding biomarkers for neurological diseases [5]. A peptide extraction using SDS-PAGE followed by electro elution onto MALDI chips identified Fibrinogen $\beta$ chain FGA/B, AHSG and SERPING1 and biomarkers of AD [6]. A complex procedure for isolating exosomes from a large volume of starting plasma using size exclusion chromatography identified super-abundant blood proteins such as immunoglobulins, HLA-A or HLB-B, SERPINS and tetraspanins [7]. It was previously established that organic extraction was an effective method to prefractionate serum peptides [8]. Differential staining of 2 dimensional PAGE indicated differences in apolipoprotein isoforms between AD versus idiopathic normal pressure hydrocephalus patients [9]. Plasma protein profiling of mild cognitive impairment and Alzheimer's disease using iTRAQ quantitative proteomics identified apolipoproteins including clusterin (APOJ), transferrin, and Inter-alpha-trypsin inhibitor (ITIH4) [10]. Synuclein is thought to be a marker of Parkinson's disease and it has been studied in AD [11]. Protein arrays showed that ectodysplasin A2 receptor (EDA2R), Poliovirus receptor (PVR) and discoidin domain receptor family, member 1 (DDR1) were potential biomarkers of AD [12]. An array of nucleic acid aptamers was used to identify 44 proteins that apparently showed modest enrichments in AD but that showed no significant protein interactions, and APOE was the strongest correlate with amyloid burden [13]. A panel of apolipoprotein and acute phase or common response proteins was shown to discriminate between levels of amyloid burden [14]. Haptoglobin, serpin, Alpha-2-antiplasmin, and Antithrombin-III as well as Complement C4-A were increased in first-onset schizophrenia patients [15]. Alzheimer risk was associated with variation in the copy number of the Complement Receptor 1 thus increasing $\mathrm{C} 3 \mathrm{~b} / \mathrm{C} 4 \mathrm{~b}$ binding sites [16]. The activation of the complement system by the myelin sheath [17] is consistent with elevated plasma levels of complement C4 that correlated with Multiple Sclerosis disease activity [18].

The neurological conditions Schizophrenia and multiple sclerosis have both been linked to the function of the complement system that prunes neural connections [18]. Plasma levels of Complement 4a protein are increased in Alzheimer's disease [19]. X-Aptamers identified C4A and $A p o B$ as potential markers for schizophrenia from blood [20]. Complement and microglia cells of the innate immune system mediate early synapse loss in a mouse model of Alzheimer's dementia [21]. High levels of complement proteins were observed in astrocyte-derived exosomes of Alzheimer disease [22]. Complement protein levels in astrocyte-derived exosomes were abnormal in mild cognitive impairment [23]. Complement C4, gelsolin and the 14-3-3 Epsilon scaffold (YWHAE) were observed in both the brain and blood [1, 24]. Autoantibody profiling of glioma serum samples using arrays identified the 14-3-3 adaptor/scaffold YWHAH [25]. The presence of autoantibodies may indicate that the mechanism of AD has an autoimmune component [26]. Neuroprotective effects of regulatory $\mathrm{T}$ cells were observed in a Alzheimer's disease model [27]. Increased levels of 14-3-3 gamma and epsilon proteins were observed in the brain of patients with Alzheimer's disease and Down syndrome [24]. Myosin 1b is known to promote axon formation by regulating actin wave propagation and thus the dynamics of the growth cone [28]. The Genetic Loci ASTN2, DPP4 and MAST4 were associated with hippocampal volume [29]. A BECN1 mutation mediated autophagic sequestration of amyloid oligomers and improved cognition in Alzheimer's disease [30]. Profiling the human hippocampal proteome at all pathologic stages of Alzheimer's disease revealed an increase in cytoskeleton associated 
proteins RIMS1 and GRIK4 and synaptic proteins, such as BSN, LIN7A, DLG2, -3, and -4 [31]. Associations were observed between Hippocampal Morphometry and Neuropathologic Markers of Alzheimer's disease [32]. BAG-1 is a protective factor that is increased in the brains of AD patients [33-35]. There is evidence that targeting TNF may prevent inflammatory damage in $\operatorname{AD}[36,37]$. The provision of nerve growth factor (NGF) has been suggested as a treatment for AD [38, 39]. Striated Muscle Enriched Protein Kinase (SPEG) and UBE2L3 that may be structurally and functionally related to Ubiquitin Conjugating Enzyme E2 G1 (UBE2G1) were differentially methylated genes associated with cognitive impairment [40] and circulating UBE2G1 transcripts may have potential as biomarkers [41]. Disrupted in Schizophrenia 1 (DISC1), TRAF2 and NCK Interacting Kinase (TNIK) have been identified from genomic sequence experiments as risk factor in $\mathrm{AD}[42,43]$. DISC1 is known to be expressed in neurological tissue and found in the blood and has been linked to mechanisms of Alzheimer's pathology [44-47].

Analysis of Prokaryotic and Eukaryotic protein samples by LC-ESI-MS/MS indicates that observation frequency is a more informative parameter than peptide intensity for relative protein quantification by LC-ESI-MS/MS [48]. Random and independent sampling [49] is required for inference by classical statistical methods and has detected and confidently identified some $\geq 14,000$ human protein Gene Symbols with more than 5 fully tryptic peptides by the stringent X!TANDEM algorithm from plasma [50]. In contrast, the use of a form of transect sampling has detected a few hundred proteins in serum or plasma [51-54].

Each clinical sample must be partitioned into multiple sub-fractions to achieve sensitivity $[55,56]$ for random and independent sampling by analytical C18 LC-ESIMS/MS [55] that creates a large computational challenge. The MS/MS spectra from thousands of LC-ESI-MS/MS experiments from multiple clinical treatments and sites may be fit to peptides by the X!TANDEM and SEQUEST algorithms [57, 58]. The 32-bit computer lacked the power to identify and compare all the peptides of all the proteins of the many sub-factions from each patient in a large multisite clinical experiment [59]. The combination of step wise organic partition [55], random and independent sampling by nano electrospray LC-ESI-MS/ MS [49], and 64-bit computation with SQL SERVER/R [60] permitted the sensitive detection of peptides and/or phosphopeptides. Thus, variation in the cleavage of parent protein chains and complexes from human plasma were compared between $\mathrm{AD}$ versus control alongside other diseases and normal plasma by the classical statistical approaches of the Chi Square test of observation frequency, STRING analysis of the identified proteins and univariate or two-way ANOVA of protein and peptide intensity [61-64]. There was striking agreement between the results of LC-ESI-MS/MS of the blood peptides with the known proteins and genes that participate in the pathology of Alzheimer's dementia and the analysis revealed new neurological proteins specific to $A D$ in circulation.

\section{Materials and methods \\ Materials}

Human EDTA plasma with no identifying information were received and analyzed under the Ryerson Ethical Review Board Protocol REB 2015-207: Treatmentblinded, Alzheimer's dementia (AD), Multiple sclerosis (MS) and institution-matched normals were obtained from Amsterdam University Medical Centers, Vrije Universiteit Amsterdam; ICU-Sepsis versus ICU Control EDTA plasma were obtained from Clinical Evaluation Research Unit, Kingston General Hospital, Kingston Ontario Canada; Ovarian and breast cancer samples along with female only controls were obtained from the Ontario Tumor bank of the Ontario Institute of Cancer Research, Toronto Ontario; Heart attack (venous and arterial) versus pre-operative orthopedic surgery controls were obtained from St Joseph's Hospital of McMaster University; In addition, EDTA plasma samples collected onto ice as a baseline degradation controls were obtained from IBBL Luxembourg [49, 65]. C18 zip tips were obtained from Millipore (Bedford, MA), C18 HPLC resin was from Agilent (Zorbax 300 SB-C18 5-micron). Solvents were obtained from Caledon Laboratories (Georgetown, Ontario, Canada). All other salts and reagents were obtained from Sigma-Aldrich-Fluka (St Louis, MO) except where indicated.

\section{Sample preparation}

A total of $12 \mathrm{AD}$ and 12 normal Control Human EDTA plasma samples $(200 \mu \mathrm{l})$ were precipitated with 9 volumes of acetonitrile (90\% ACN) [8], followed by extraction of the pellet using a step gradient to achieve selectivity across sub-fractions and thus greater sensitivity [55]. Disposable plastic $2 \mathrm{ml}$ sample tubes and plastic pipette tips were used to handle samples. The acetonitrile suspension was separated with a centrifuge at 12,000 RCF for $5 \mathrm{~min}$. The acetonitrile supernatant, that contains few peptides, was collected, transferred to a fresh sample tube and dried in a rotary lyophilizer. The organic precipitate (pellet) that contains a large total amount of endogenous polypeptides [8] was manually re-suspended using a step gradient of increasing water content to yield 10 fractions from those soluble in $90 \% \mathrm{ACN}$ to $10 \% \mathrm{ACN}$, followed by $100 \% \mathrm{H}_{2} \mathrm{O}$ and then $5 \%$ formic acid [55]. The extracts 
were clarified with a centrifuge at 12,000 RCF for $5 \mathrm{~min}$. The extracted sample fractions were dried under vacuum in a rotary lyophyllizer and stored at $-80^{\circ} \mathrm{C}$ for subsequent analysis.

\section{Preparative $\mathrm{C} 18$ chromatography}

Preparative C18 separation provided the best results for peptides and phosphopeptides analysis in a "blind" test [66]. Solid phase extraction with C18 for LC-ESI-MS/ MS was performed as previously described $[8,56,64$, 67, 68]. The C18 chromatography resin (Zip Tip) was wet with $65 \%$ acetonitrile before equilibration in water with $5 \%$ formic acid. The plasma extract was dissolved in $200 \mu \mathrm{l}$ of $5 \%$ formic acid in water. The resin was washed with at least five volumes of the same binding buffer. The resin was eluted with $\geq 3$ column volumes of $65 \%$ acetonitrile $(2 \mu \mathrm{L})$ in $5 \%$ formic acid. In order to avoid crosscontamination the preparative $\mathrm{C} 18$ resin was discarded after a single use.

\section{LC-ESI-MS/MS}

In order to entirely prevent any possibility of cross contamination, a new disposable nano analytical HPLC column and nano emitter was fabricated for recording each patient sample-fraction set. The ion traps were cleaned and tested for sensitivity with angiontensin and glu fibrinogen prior to recordings. The new column was conditioned and quality controlled with a mixture of three non-human protein standards [61] using a digest of Bovine Cytochrome $\mathrm{C}$, Yeast alcohol dehydrogenase (ADH) and Glycogen Phosphorylase B to confirm the sensitivity and mass accuracy of the system prior to each patient sample set. The statistical validity of the linear quadrupole ion trap for LC-ESI-MS/MS of human plasma [55] was in agreement with the results from the 3D Paul ion trap [61, 62, 69, 70]. The stepwise extractions were collected and desalted over $\mathrm{C} 18$ preparative micro columns, eluted in $2 \mu \mathrm{L}$ of $65 \% \mathrm{ACN}$ and $5 \%$ formic acid, diluted ten-fold with $5 \%$ formic acid in water and $5 \% \mathrm{ACN}$, and immediately loaded manually into a $20 \mu \mathrm{l}$ metal sample loop before injecting onto the analytical column via a Rheodyne injector. Endogenous peptide samples were analyzed over a discontinuous gradient generated at a flow rate of $\sim 10$ micro litres per minute with an Agilent 1100 series capillary pump and split upstream of the injector during recording to about $200 \mathrm{nl}$ per minute. The separation was performed with a C18 $(150 \mathrm{~mm} \times 0.15 \mathrm{~mm})$ fritted capillary column. The acetonitrile profile was started at $5 \%$, ramped to $12 \%$ after $5 \mathrm{~min}$ and then increased to $65 \%$ over $\sim 90 \mathrm{~min}$, remained at $65 \%$ for $5 \mathrm{~min}$, decreased to $50 \%$ for $15 \mathrm{~min}$ and then declined to a final proportion of $5 \%$ prior to injection of the next step fraction from the same patient.
The nano HPLC effluent was analyzed by ESI ionization with detection by MS and fragmentation by MS/MS with a linear quadrupole ion trap [71]. The instrument was set to collect the precursors for up to 200 milli seconds prior to MS/MS fragmentation with up to four independent MS/MS fragmentations per precursor ion. Individual, independent samples from disease, normal and ice cold control were precipitated, fractionated over a step gradient and collected over $\mathrm{C} 18$ for manual injection. The level of replication in the LC-ESI-MS-MS experiments was typically between 9 to 26 independent patient plasma samples for each of the treatments with $12 \mathrm{AD}$ and 12 AD control samples fractionated for analysis.

\section{Correlation analysis}

Previous comparisons of high-resolution versus lowresolution analysis of peptides have shown that different mass spectrometric instruments show strong agreement on the high abundance proteins but that the Linear Quadrupole Ion Trap has the advantage of being more sensitive, economical, uses less power and gives off much less heat as well as having the smallest bench-top foot print [64, 72-75]. Thus, it is possible to use a battery of Linear Quadrupole Ion Traps to make multi site clinical trials using random and independent sampling followed by targeted quantification using the same simple, sensitive and robust instrument $[49,65]$. Correlation analysis of ion trap data was performed using a goodness of fit test by X!TANDEM [57] and by cross-correlation using SEQUEST [76] on separate servers to match tandem mass spectra to peptide sequences from the Homo sapiens RefSeq, Ensembl, SwissProt, including hypothetical proteins XP or Genomic loci $[60,68,72]$. Setting the mass tolerance to a range including heavy isotopes generates a greater number of strong correlations to the protein in the expected protein standard thus reducing the total error in proteomics $[48,77,78]$. The X!TANDEM default ion trap data settings of $\pm 3 \mathrm{~m} / \mathrm{z}$ from precursor peptides considered from 300 to $2000 \mathrm{~m} / \mathrm{z}$ with a tolerance of $0.5 \mathrm{Da}$ error in the fragments were used [56, 57, $62,69,70,78]$. Peptides from proteins may show phosphorylation at serine, threonine, and tyrosine (STY) and it is common post-translational modification of proteins [79]. The best fit peptide of the MS/MS spectra to fully tryptic and/or phosphotryptic peptides at charge states of +2 versus +3 were accepted with additional acetylation, or oxidation of methionine and with possible loss of water or ammonia. The resulting accession numbers, actual and estimated masses, correlated peptide sequences, peptide intensity and MS/MS fragments to peptide fit scores, resulting protein sequences and other 
associated data were captured and assembled together in an SQL Server relational database [60].

\section{Data sampling, sorting, transformation and visualization} Endogenous peptides with precursors greater than 10,000 (E4) arbitrary counts were searched as fully tryptic peptides and/or phosphopeptides, the results were combined, and compared in SQL Server/R. The protein $\mathrm{p}$-values and FDR q-values were computed from organic extraction or chromatography of blood fluid and the peptide-to-protein distribution of the precursor ions of greater than $\sim 10,000$ (E4) counts were compared to a null (i.e. known false positive) model of noise or computer generated random MS/MS spectra $[49,61,62,69$, 70, 77]. Peptides may be identified from the fit of MS/ MS spectra to peptide sequences by X!TANDEM [57] that permits the accurate estimate of the type I error rate (p-value) of protein identification that may be corrected by the method Benjamini and Hochberg [80] to yield the FDR (q-value) [49, 55, 77]. Random or noise MS/MS spectra distributions were used to control the type I error of experimental MS/MS spectra correlations to tryptic peptides: The peptide and protein observation counts (frequency) may be analyzed using classical statistic methods such as Chi Square analysis [69, 81]. $\log _{10}$ transformation of precursor intensity yields a normal distributions that permits comparison of peptide and protein expression levels by ANOVA [62, 63]. The SQL Server system permits the direct interrogation of the related data by the open source R statistical system without proteomic-specific software packages. The use of SQL/R has permitted the detailed statistical analysis of randomly and independently sampled LC-ESI-MS/ MS data from multiple hospitals in parallel that would be requisite for a multisite clinical trial $[50,81]$. The linear quadrupole ion trap provided the precursor ion intensity values and the peptide fragment MS/MS spectra. The peptides and proteins were identified from MS/MS spectra by X!TANDEM and were counted by the SEQUEST algorithm. Redundant correlations to MS/MS at different charge states or to different sequences may be a source of type I error that may be filtered out by a complex key in SQL Server. The MS and MS/MS spectra together with the results of the X!TANDEM and SEQUEST algorithms were parsed into an SQL Server database and filtered [60] before statistical and graphical analysis with the generic $\mathrm{R}$ data system [60-63, 72]. The peptide-to-protein correlation frequency counts for each gene symbol were summed over AD versus the matched control to correct the observation frequency for the Chi Square test using Eq. 1:

$$
\left(\mathrm{AD}-\mathrm{AD} \_ \text {control }\right)^{2} /(\mathrm{AD} \text { _control }+1)
$$

The precursor intensity data for MS/MS spectra were $\log _{10}$ transformed, tested for normality and analyzed across institution/study and diseases versus controls by means, standard errors and ANOVA [61-63]. The entirely independent analysis of the precursor intensity by ANOVA versus multiple treatments and controls was achieved using a 64-bit $R$ server.

\section{Results}

Partition of plasma samples using differential solubility in organic/water mixtures was combined with random and independent sampling by LC-ESI-MS/ MS and detected peptides from proteins that were more frequently observed and/or showed greater intensity in $A D$ versus $A D$ _control. Here four independent lines of evidence, Chi Square analysis of observation frequency, previously established structural/functional relationships from STRING, ANOVA analysis of peptide intensity, and agreement with the previous genetic or biochemical experiments, all indicated that there was significant statistical and biological variation in the peptides of $\mathrm{AD}$ patients compared to $\mathrm{AD}$ control and other diseases or normal plasma samples.

\section{LC-ESI-MS/MS}

The pool of endogenous tryptic (TRYP) and/or tryptic phosphopeptides (STYP) were randomly and independently sampled by liquid chromatography, nano electrospray ionization and tandem mass spectrometry (LC-ESI-MS/MS) [49] from AD vs AD Control or other disease and normal plasma, and ice cold controls to serve as a baseline [65, 82]. Some $15,968,550 \mathrm{MS} /$ MS spectra $\geq E 4$ intensity counts were correlated by the SEQUEST and X!TANDEM algorithms to match the MS/MS spectra to tryptic peptides within proteins. The correlations from SEQUEST were filtered to retain only the best fit by charge state and peptide sequence in SQL Server to avoid re-use of the same MS/MS spectra. The distinct results were then analyzed by the generic $\mathrm{R}$ statistical system in a matrix of disease and controls that reveals the set of blood peptides and proteins specific to each disease state. The statistical validity of the extraction and sampling system were previously established by computation of protein gene symbols $\mathrm{p}$-values and FDR corrected q-values by the method of Benjamini and Hochberg [80] and frequency comparison to false positive noise or random MS/MS spectra $[48,61,63,69,70$, $77,78]$. 


\section{Frequency correction}

Chi Square ( $x 2)$ may be used to compare discrete, "counting" variables such as observation frequency. A total of 486,367 MS/MS $\geq$ E4 counts were collected from AD and $424,591 \mathrm{MS} / \mathrm{MS} \geq \mathrm{E} 4$ counts were collected from the AD Normal control plasma and these sums were used to correct observation frequency. Similar results were obtained from comparisons corrected on the basis of total correlation sum in each treatment (not shown). Removing the treatment-blind revealed many proteins that showed large increases or decreases in observation frequency between $\mathrm{AD}$ versus the matched $\mathrm{AD}$ normal resulting in large Chi Square values (Fig. 1).

\section{Comparison of AD to matched control by Chi square analysis}

The gene symbols with the most significant Chi Square values $(x 2 \geq 90)$ from tryptic peptides included kinesin KIF12, disrupted in schizophrenia 1 (DISC1), the auto immune target olfactory receptor 8 (OR8B12) [83] and Monocyte Chemotactic Induced Zinc Finger $\mathrm{CCCH}$ Domain-Containing Protein Endoribonuclease (ZC3H12A) that regulates cell death [84]. Many proteins similar to olfactory receptors were observed with multiple peptide correlation by X!TANDEM and SEQUEST (Additional file 6: Table S6). The observation of many peptides correlated to proteins similar to olfactory
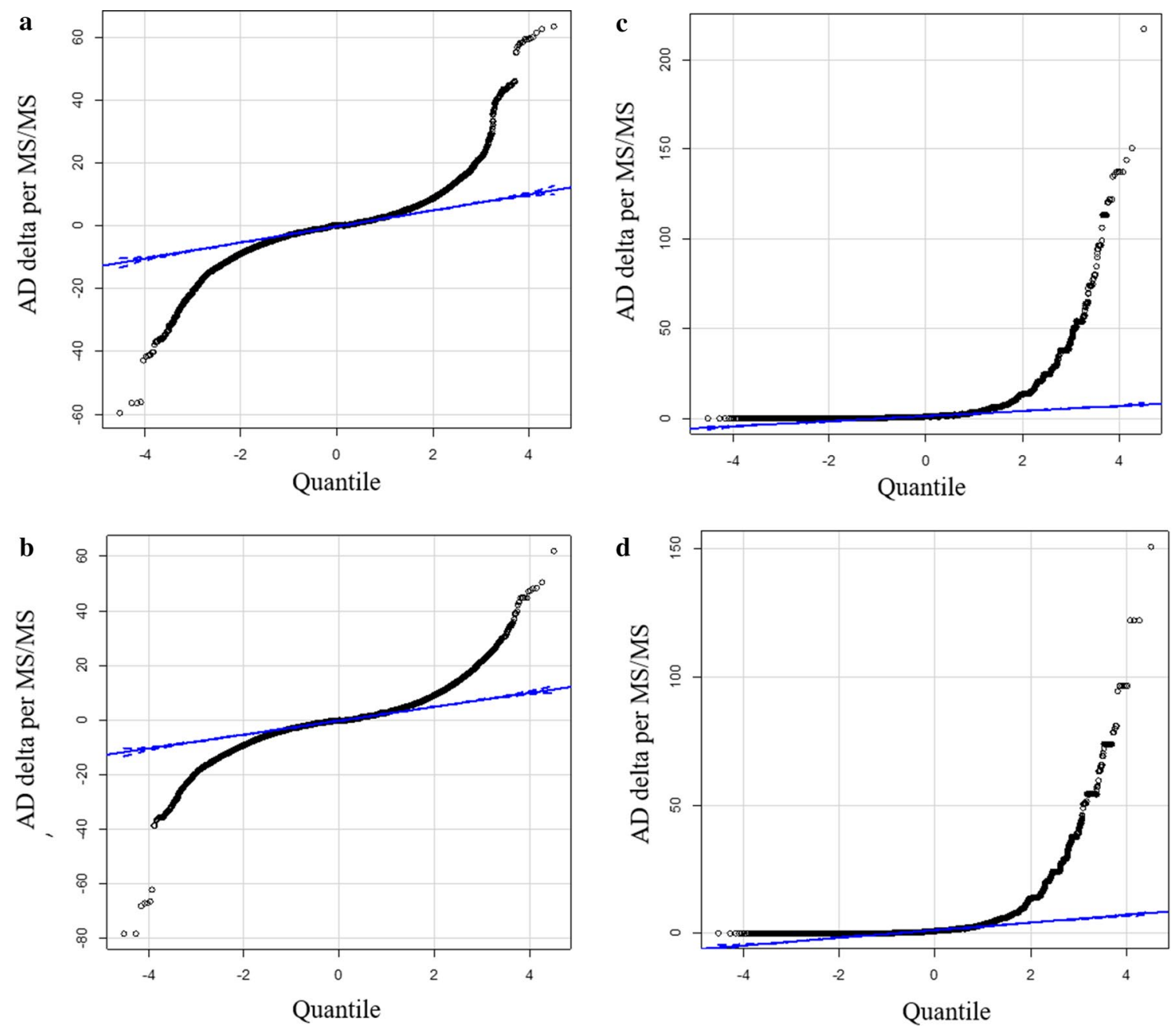

Fig. 1 Quantile plots of the corrected difference in observation frequency and Chi Square values of the AD ( $n \geq 10)$ versus Normal Control ( $n \geq 9)$. Panels: a Quantile plot of the observation frequency of tryptic peptides from AD versus Normal Control.; $\mathbf{b} \times 2$ plot of the observation frequency of tryptic peptides from AD versus Normal Control tryptic peptides; c Quantile plot of the observation frequency of tryptic STYP peptides from AD versus AD control; $\mathbf{d}$ X2 plot of the observation frequency of tryptic STYP peptides from AD versus AD control tryptic peptides 
Table 1 AD specific proteins detected by fully tryptic peptides (TRYP) and/or fully tryptic phosphopeptides (STYP) that show a Chi Square $(x 2)$ value of $\geq 43$. The average Chi Square $(x 2)$ value per gene symbol was computed in $R$

\begin{tabular}{|c|c|c|c|c|c|}
\hline Gene_symbol & TRYP_X2 & Proteins & Gene_symbol & STYP_X2 & Proteins \\
\hline $\mathrm{KIF} 12$ & 170 & 2 & MOK & 151 & 1 \\
\hline DISC1 & 104 & 29 & SMIM19 & 96 & 2 \\
\hline OR8B12 & 96 & 1 & NXNL1 & 94 & 1 \\
\hline $\mathrm{ZC} 3 \mathrm{H} 12 \mathrm{~A}$ & 94 & 1 & SLC24A2 & 85 & 2 \\
\hline TNF & 81 & 3 & CUX1 & 78 & 1 \\
\hline TBC1D8B & 74 & 1 & AHRR & 74 & 1 \\
\hline GALNT3 & 74 & 1 & C10orf90 & 74 & 1 \\
\hline EME2 & 74 & 1 & MAEA & 74 & 1 \\
\hline CD1B & 74 & 1 & SRSF8 & 74 & 1 \\
\hline BAG1 & 73 & 2 & TBATA & 74 & 1 \\
\hline CPSF2 & 68 & 2 & TNIK & 74 & 1 \\
\hline MMP15 & 65 & 1 & UBE2G1 & 74 & 2 \\
\hline DNAJC2 & 65 & 3 & PDE4C & 70 & 10 \\
\hline PHACTR4 & 64 & 1 & PCGF2 & 69 & 2 \\
\hline OR8B3 & 64 & 1 & KIR3DP1 & 65 & 1 \\
\hline GCK & 64 & 1 & TJP2 & 65 & 1 \\
\hline EXOSC7 & 64 & 1 & CPNE8 & 63 & 2 \\
\hline HMGA1 & 63 & 4 & NGF & 59 & 1 \\
\hline NT5C3A & 63 & 2 & ZNF671 & 57 & 2 \\
\hline POLR1A & 59 & 1 & ADAMTS12 & 54 & 1 \\
\hline NET1 & 57 & 1 & APC & 54 & 1 \\
\hline MGC24039 & 57 & 1 & $\mathrm{ASAH} 2 \mathrm{~B}$ & 54 & 1 \\
\hline SYTL4 & 56 & 2 & BRCA1 & 54 & 1 \\
\hline CLDN7 & 56 & 2 & C11orf89 & 54 & 1 \\
\hline OSBPL1A & 55 & 2 & CBWD7 & 54 & 1 \\
\hline VTI1B & 54 & 1 & DAPK3 & 54 & 1 \\
\hline TRIM14 & 54 & 1 & DCAF15 & 54 & 1 \\
\hline TPH1 & 54 & 1 & GPR98 & 54 & 1 \\
\hline TNFRSF14 & 54 & 1 & GRID2 & 54 & 1 \\
\hline SORBS3 & 54 & 1 & HSP90AA2 & 54 & 1 \\
\hline SLC30A1 & 54 & 1 & KIAA1467 & 54 & 1 \\
\hline RSRC2 & 54 & 1 & KIR222 & 54 & 1 \\
\hline PDCD5 & 54 & 1 & L3MBTL2 & 54 & 1 \\
\hline PANO & 54 & 1 & LOC389605 & 54 & 1 \\
\hline METTL17 & 54 & 1 & NBS1 & 54 & 1 \\
\hline MATK & 54 & 1 & NPR2 & 54 & 3 \\
\hline ILK & 54 & 1 & $\mathrm{OR} 8 \mathrm{H} 2$ & 54 & 1 \\
\hline FL00366 & 54 & 1 & PDZD9 & 54 & 1 \\
\hline EPHX3 & 54 & 1 & PTTG2 & 54 & 2 \\
\hline DYM & 54 & 1 & RAD52 & 54 & 1 \\
\hline CSNK2B-LY6G5B-1181 & 54 & 1 & RALGAPA2 & 54 & 1 \\
\hline SPEG & 54 & 4 & SIRPA & 54 & 3 \\
\hline $\mathrm{CDH} 13$ & 52 & 5 & SLMAP & 54 & 1 \\
\hline SLC36A2 & 51 & 5 & SRM & 54 & 1 \\
\hline SMPD3 & 51 & 3 & TSPY8 & 54 & 1 \\
\hline WDR82 & 51 & 1 & XP32 & 54 & 1 \\
\hline TRAF4 & 51 & 1 & XPC & 54 & 1 \\
\hline SGK3 & 51 & 1 & RP11-632C17_A.1-001 & 54 & 1 \\
\hline
\end{tabular}


Table 1 (continued)

\begin{tabular}{llllcc}
\hline Gene_symbol & TRYP_X2 & Proteins & Gene_symbol & STYP_X2 & Proteins \\
\hline NCAPD3 & 51 & 1 & DENND3 & 51 & 2 \\
\hline GRXCR1 & 51 & 1 & CDC27 & 51 & 1 \\
ANKS6 & 49 & 1 & FLJ32063 & 51 & 51 \\
CYP4A11 & 48 & 8 & NOC100129307 & 51 & 1 \\
EXOC3L4 & 46 & 2 & NUP210 & 51 & 1 \\
POC1A & 46 & 2 & OGFOD3 & 51 & 1 \\
FUT9 & 46 & 2 & MST1R & 50 & 1 \\
MAP3K19 & 46 & 4 & PTPLA & 50 & 1 \\
CHD9 & 46 & 1 & PRKCD & 50 & 1 \\
USP30 & 44 & 1 & MROH9 & 49 & 2 \\
DCUN1D2 & 44 & CHMP3 & 49 & 1 \\
BOK & 44 & C2 & 48 & 3 \\
TAGLN2 & 44 & 3 & & 48
\end{tabular}

The full set of gene symbols with Chi Square $(x 2) \geq$ is shown in Additional file 1:Table S1

receptors by both X!TANDEM and SEQUEST seem to indicate that genes for olfactory receptors are transcribed into RNA and give rise to measurable amounts of translated proteins like other protein genes [85]. The most significant gene symbols $(x 2 \geq 90)$ from phosphotryptic peptides included MOK protein kinase, the truncated form of thioredoxin, Retinosa pigmentosa, the cell death regulator required for cone viability (NXNL1) and unknown small membrane protein 19 (SMIM19). A set of $\sim 50$ gene symbols showed a substantial difference $\geq 9$ counts and a $X 2 \geq 25(\mathrm{p} \leq 0.001)$ between $A D$ versus the matched AD Control. For $\chi^{2}$ analysis the tryptic peptides (TRYP) were computed independently from the phospho-tryptic peptides. Common plasma proteins such as $\mathrm{C} 2, \mathrm{C}$, and $\mathrm{C} 1 \mathrm{QBP}$ were observed to show significant differences in observation frequency between $A D$ versus $A D$ control. Specific peptides and/or phosphopeptides from cellular proteins, membrane proteins, nucleic acid binding proteins, signaling factors, metabolic enzymes and others including uncharacterized proteins showed significantly greater observation frequency in $\mathrm{AD}$ (Table 1). Gene symbols specific to AD included TNF, TBC1D8B, GALNT3, EME2, CD1B, BAG1, CPSF2, MMP15, DNAJC2, PHACTR4, OR8B3, GCK, EXOSC7, HMGA1 and NT5C3A among others from tryptic peptides. Similarly, increased frequency of tryptic phosphopeptides were observed from SLC24A2, CUX1, AHRR, C10orf90, MAEA, SRSF8, TBATA, TNIK, UBE2G1, PDE4C, PCGF2, KIR3DP1, TJP2, CPNE8, and NGF amongst others. The observation frequency of peptides from DISC1 was higher in AD compared to any other disease or control treatment. Observation frequency may be the best measure of relative abundance [48] and the full list of Chi Square results $\left(x^{2} \geq 9, \mathrm{p} \leq 0.01\right)$ are found in the Supplemental Data that is the most important result of this study (Additional file 1: Table S1).

\section{STRING network analysis}

The gene symbols that varied between $A D$ versus $A D$ control with average Chi Square $\chi^{2} \geq 25 \quad(\mathrm{p} \leq 0.01)$ revealed a complex network of protein gene symbols [86] of 1163 nodes with 5017 edges (PPI enrichment p-value of 0.00602). Similarly, phosphotryptic peptides (STYP) with gene symbol Chi Square $(\chi 2) \geq 25$ revealed a network of proteins [86] with 1224 nodes and 5066 edges (PPI enrichment p-value of 0.00342). For the purposes of illustration, the proteins that showed at least 9 greater observations (Delta) and $\mathrm{X} 2$ values greater than 25 $(\mathrm{p}<0.001)$ are shown as separate as tryptic (TRYP), versus phospho-tryptic (STYP), STRING networks (Figs. 2 and 3). STRING analysis showed an increase in cytoplasmic proteins and proteins associated with alternate splicing, exocytosis of luminal proteins, and proteins involved in the regulation of the cell cycle, mitochondrial functions or metabolism and apoptosis (Table 2). The full list of Gene Symbols from tryptic peptides, phospho tryptic peptides and the resulting STRING analysis may be found in Additional files 2, 3, 4, 5: Table S2-S5. 
Table 2 The STRING analysis of the AD specific protein network where corrected difference in observation frequency and the Chi Square value were both greater than 15 that showed: nodes, 1248; number of edges, 5604; average node degree, 8.98; avg. local clustering coefficient, 0.321 ; expected number of edges, 5362; PPI enrichment p-value, 0.000516

\begin{tabular}{|c|c|c|c|c|}
\hline Term ID & Term description & $\begin{array}{l}\text { Observed gene } \\
\text { count }\end{array}$ & $\begin{array}{l}\text { Background } \\
\text { gene count }\end{array}$ & False discovery rate \\
\hline KW-0025 & Alternative splicing & 821 & 10223 & $1.98 \mathrm{E}-18$ \\
\hline KW-0963 & Cytoplasm & 379 & 4972 & 0.0178 \\
\hline GO:0005829 & cytosol & 405 & 4958 & 0.0000291 \\
\hline GO:0044444 & cytoplasmic part & 695 & 9377 & 0.0000291 \\
\hline GO:0005737 & Cytoplasm & 809 & 11238 & 0.0000436 \\
\hline GO:0005622 & Intracellular & 983 & 14286 & 0.0007 \\
\hline GO:0044424 & Intracellular part & 966 & 13996 & 0.0007 \\
\hline GO:0043226 & Organelle & 866 & 12432 & 0.0022 \\
\hline GO:0005623 & Cell & 1092 & 16271 & 0.0029 \\
\hline GO:0044464 & Cell part & 1090 & 16244 & 0.003 \\
\hline GO:0043229 & Intracellular organelle & 848 & 12193 & 0.0034 \\
\hline GO:0043231 & Intracellular membrane-bounded organelle & 729 & 10365 & 0.0096 \\
\hline GO:0044422 & Organelle part & 649 & 9111 & 0.0096 \\
\hline GO:0005768 & Endosome & 85 & 876 & 0.0158 \\
\hline GO:0043227 & Membrane-bounded organelle & 781 & 11244 & 0.0158 \\
\hline GO:0098576 & Lumenal side of membrane & 9 & 29 & 0.0219 \\
\hline GO:0055037 & Recycling endosome & 24 & 164 & 0.024 \\
\hline GO:0044446 & Intracellular organelle part & 627 & 8882 & 0.0287 \\
\hline GO:0071556 & Integral component of lumenal side of endoplasmic reticulum & 8 & 26 & 0.0404 \\
\hline GO:0003824 & Catalytic activity & 435 & 5592 & 0.0028 \\
\hline GO:0005488 & Binding & 830 & 11878 & 0.0174 \\
\hline GO:0008152 & Metabolic process & 696 & 9569 & 0.0108 \\
\hline GO:0051726 & Regulation of cell cycle & 115 & 1129 & 0.0108 \\
\hline GO:0010564 & Regulation of cell cycle process & 76 & 684 & 0.0175 \\
\hline GO:1901990 & Regulation of mitotic cell cycle phase transition & 47 & 351 & 0.0175 \\
\hline GO:0045786 & Negative regulation of cell cycle & 61 & 517 & 0.0186 \\
\hline GO:0010821 & Regulation of mitochondrion organization & 26 & 148 & 0.0187 \\
\hline GO:0044237 & Cellular metabolic process & 637 & 8797 & 0.0187 \\
\hline GO:0044238 & Primary metabolic process & 638 & 8808 & 0.0187 \\
\hline GO:0071704 & Organic substance metabolic process & 657 & 9135 & 0.0187 \\
\hline GO:1901987 & Regulation of cell cycle phase transition & 49 & 385 & 0.0187 \\
\hline GO:0008104 & Protein localization & 172 & 1966 & 0.0208 \\
\hline GO:0007346 & Regulation of mitotic cell cycle & 67 & 608 & 0.0212 \\
\hline GO:0006807 & Nitrogen compound metabolic process & 603 & 8349 & 0.0286 \\
\hline GO:0009056 & Catabolic process & 162 & 1859 & 0.0286 \\
\hline GO:0009987 & Cellular process & 994 & 14652 & 0.0286 \\
\hline GO:0010823 & Negative regulation of mitochondrion organization & 13 & 50 & 0.0286 \\
\hline GO:0044248 & Cellular catabolic process & 147 & 1646 & 0.0286 \\
\hline GO:0048583 & Regulation of response to stimulus & 306 & 3882 & 0.0286 \\
\hline GO:0051641 & Cellular localization & 186 & 2180 & 0.0286 \\
\hline GO:0080134 & Regulation of response to stress & 120 & 1299 & 0.0286 \\
\hline GO:0097190 & Apoptotic signaling pathway & 39 & 295 & 0.0286 \\
\hline GO:1901564 & Organonitrogen compound metabolic process & 401 & 5281 & 0.0286 \\
\hline GO:0032270 & Positive regulation of cellular protein metabolic process & 134 & 1496 & 0.0315 \\
\hline GO:0019538 & Protein metabolic process & 324 & 4194 & 0.0389 \\
\hline GO:0044403 & Symbiont process & 68 & 650 & 0.0389 \\
\hline GO:0007093 & Mitotic cell cycle checkpoint & 24 & 153 & 0.0434 \\
\hline
\end{tabular}


Table 2 (continued)

\begin{tabular}{|c|c|c|c|c|}
\hline Term ID & Term description & $\begin{array}{l}\text { Observed gene } \\
\text { count }\end{array}$ & $\begin{array}{l}\text { Background } \\
\text { gene count }\end{array}$ & False discovery rate \\
\hline GO:0044260 & Cellular macromolecule metabolic process & 472 & 6413 & 0.0434 \\
\hline GO:0016032 & Viral process & 61 & 571 & 0.0439 \\
\hline GO:0016197 & Endosomal transport & 27 & 185 & 0.0452 \\
\hline GO:0051128 & Regulation of cellular component organization & 191 & 2306 & 0.0452 \\
\hline GO:0051247 & Positive regulation of protein metabolic process & 139 & 1587 & 0.0452 \\
\hline GO:0043170 & Macromolecule metabolic process & 539 & 7453 & 0.0463 \\
\hline
\end{tabular}

Keywords, GO components, processes and functions from STRING analysis of gene symbols with a $x 2 \geq 25$ for AD versus AD control

The supporting information from the STRING analysis may be found in Additional files 2, 3, 4: Table S2-S4

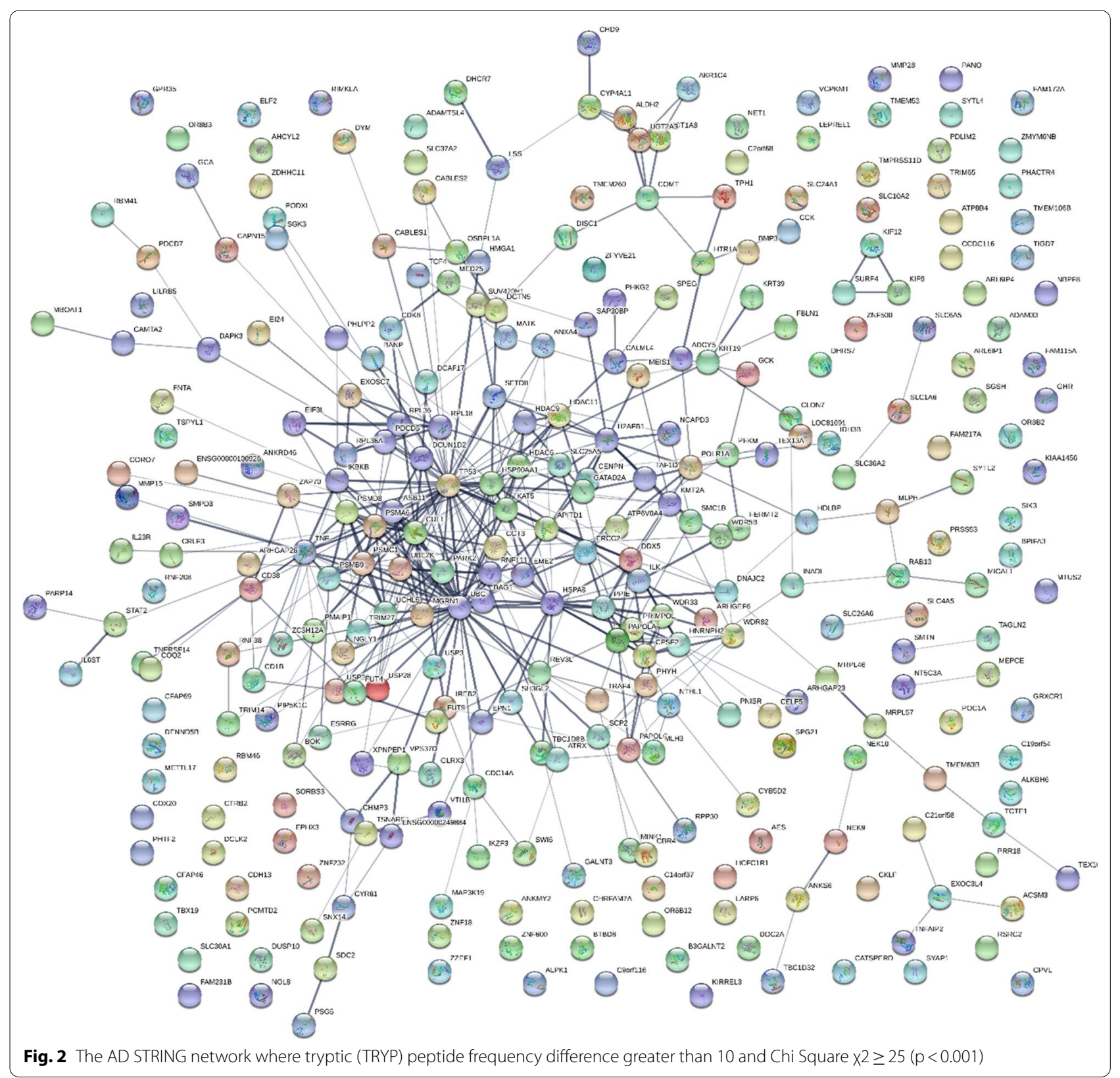




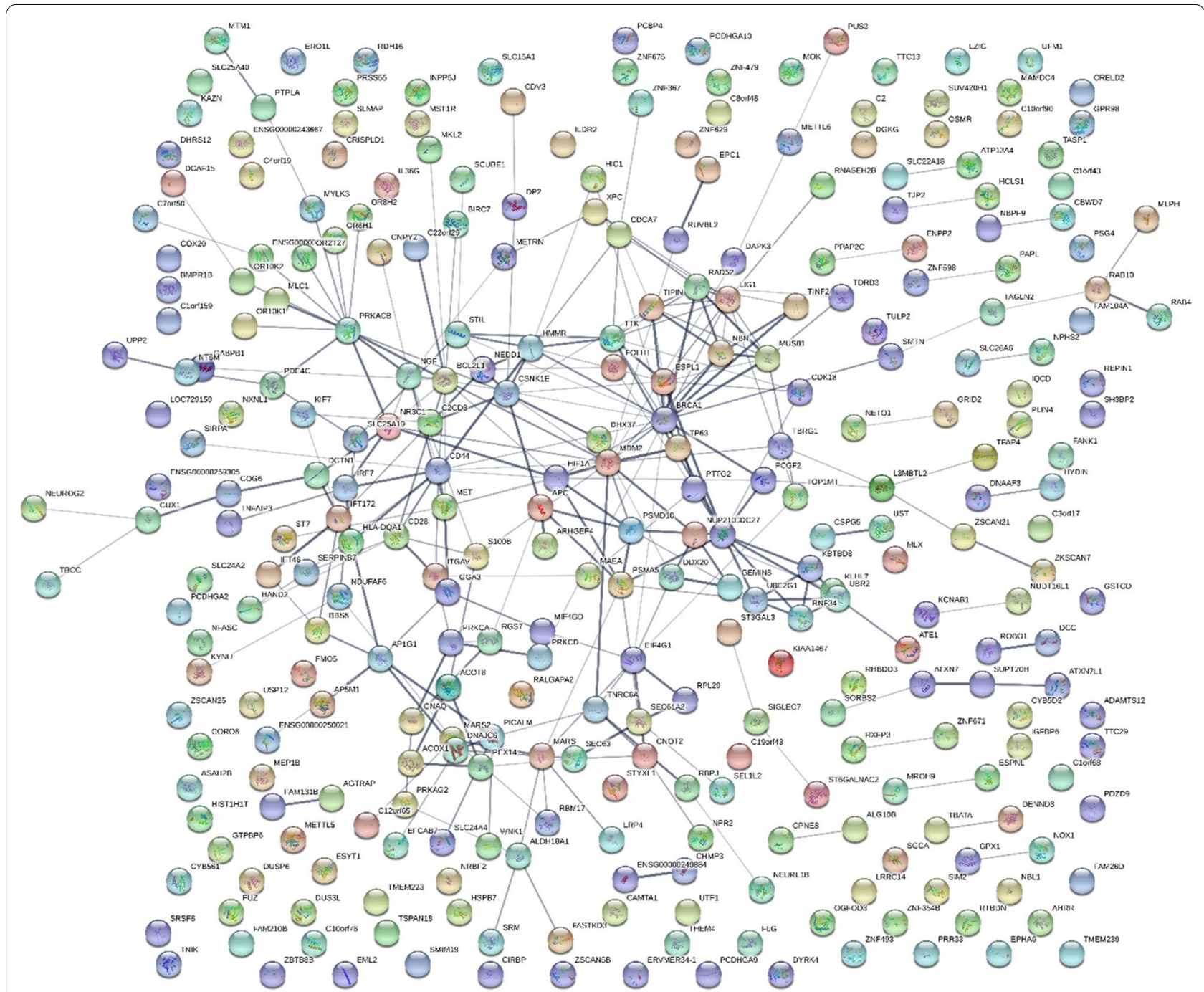

Fig. 3 The AD STRING network where phospho-tryptic (STYP) and/or tryptic peptide frequency difference greater than 10 and Chi Square X2 $\geq 25$ $(p<0.001)$

\section{Quantile box plots and ANOVA analysis across disease and control treatments}

ANOVA of peptide intensity is confounded by the different peptides observed within each protein [61] but may be an independent method to confirm the potential utility of peptides from gene symbols that showed increased observation frequency by Chi Square. Some proteins that showed greater observation frequency in $\mathrm{AD}$ also showed significant variation in protein or peptide precursor intensity compared to the AD controls and/or other disease and normal EDTA plasma by quantile box plots and ANOVA comparison. The mean precursor intensity values from gene symbols that varied by Chi Square from tryptic and/or phosphotryptic were subsequently analyzed by ANOVA [61] in $\mathrm{R}$ to look for proteins that showed significant variation in precursor intensity values across treatments $[63,64]$. Common plasma complement proteins including $\mathrm{C} 2, \mathrm{C} 7$, and C1QBP were analyzed for variation in average peptide $\log _{10}$ intensity across treatments using ANOVA and box plots (Fig. 4). Analysis of the proteins with increased observation frequency in $\mathrm{AD}$ by precursor intensity using quantile box plots and/or ANOVA confirmed significant variation in 
cellular proteins UBE2G1, SMIM19, NXNL1, PANO, MED25, MGRN1, OR8B3, MGC24039, SYTL4, RNF111, IREB2, ANKMY2, SGKL, SLC25A5, CHMP3 26, EXOSC5 among others across disease treatments (Fig. 5).

\section{Agreement of AD specific proteins from plasma with previous biochemical and genetic data} There as striking agreement between the proteins observed to be specific to AD by LC-ESI-MS/MS and the proteins previously associated with $\mathrm{AD}$ by independent biochemical, genetic or genomic methods (Table 3).

\section{Processing of DISC1 in AD versus matched controls}

The DISC1 protein that best fit the MS/MS spectra observed from human plasma was accession AAH07022.1. The average peptide intensity per gene symbol of DISC1 was higher in AD compared to AD control (Fig. 6). The processing of DISC1 included the cleavage of the terminal peptide MPGGGPQGAPAAA GGGGVSHR* and ARQCGLDSR from two hydrophilic points of DISC1 on the conserved amino terminal domain of the protein (Fig. 7) that was apparent in AD patients compared to all other diseases and controls. Thus, there was disease associated variation in the processing of DISC1 in AD versus AD controls or other diseases and normal (Table 4).

\section{DISC1 domains}

The cleavage of specific peptides from the conserved $\mathrm{N}$-terminal domain of DISC1 was most frequently observed in AD compared to all other treatments and showed greater intensity compared to other treatments. Thus, the processing of DISC1 in AD patients apparently varied compared to all other diseases and controls. The function and mechanisms of DISC1 in Alzheimer dementia are not clear [44-47, 87]. There may be some hints about the function of DISC1 by the examination of its domain architecture (Fig. 8). DISC 1 shows some significant similarity with the SMC and
SMC_prok_A domain families associated with chromosome segregation, has homology with a mechanosensitive channel MscK, and is the lone member of the coiled-coil CCDC158 superfamily (Table 5).

\section{Discussion}

Comparison of AD plasma to matched controls, alongside other disease and normals under identical conditions is a simple and direct strategy to discover variation in peptides or proteins specific to AD plasma. The aim and objective of this study was proof of concept towards a method to compare the endogenous tryptic peptides of $\mathrm{AD}$ to those from $\mathrm{AD}$ control and other diseases or normals by random and independent sampling with a set of robust and sensitive linear quadrupole ion traps where the results were collected in an SQL Server for analysis with the R statistical system. Although random and independent sampling of peptides from step-wise fractionation of plasma followed by LC-ESI-MS/MS is a time and manual labor intensive approach, it is sensitive, direct, and rests on few assumptions [49, 88]. High signal-tonoise ratio of blood peptides is dependent on sample preparation to break the sample into many sub-fractions to relieve competition and suppression of ionization and thus achieve sensitivity $[55,56,68]$ but then requires large computing power to re-assemble the sub-fractions, back into individual patient samples within treatments [55, 60, 88]. The approach shows great sensitivity and flexibility but relies on the fit of MS/MS spectra by X!TANDEM and SEQUEST $[57,58]$ to assign peptide identity and statistical analysis of precursor ion counts and intensity by Chi Square and ANOVA and so is computationally intensive $[60,61]$. The careful study of plasma degradation over time, and under various storage and preservation conditions, seems to rule out pre-clinical variation as the most important source of variation between $A D$ versus $\mathrm{AD}$ control or other disease and control treatments [49, $65,82]$. Proteins expressed in AD within the brain may be identified in the blood [1]. Proteins linked to the mechanisms of AD pathology from nuclear factors of transcription, and exon processing, proteins for transport or

\footnotetext{
(See figure on next page.)

Fig. 4 The distributions of $\log _{10}$ precursor intensity by quantile and box plots of complement proteins across the disease and control treatments. Treatment ID numbers: 1, Alzheimer normal; 2, Alzheimer's normal control STYP; 3, Alzheimer's dementia; 4, Alzheimer's dementia STYP; 5, Cancer breast; 6, Cancer breast STYP; 7, Cancer control; 8, Cancer control STYP; 9, Cancer ovarian; 10, Cancer ovarian STYP; 11, Ice Cold; 12, Ice Cold STYP; 13, Heart attack Arterial; 14 Heart attack Arterial STYP; 15, Heart attack normal control, 16, Heart attack normal Control STYP; 17, Heart attack; 18, Heart attack STYP; 19, Multiple Sclerosis normal control; 20, Multiple sclerosis normal control STYP; 21, Multiple sclerosis; 22, Multiple Sclerosis STYP, 23 Sepsis; 24, Sepsis STYP; 25, Sepsis normal control; 26, Sepsis normal control STYP. There was significant effects of treatments and peptides by two-way ANOVA. Analysis of the proteins shown across treatments produced a significant F Statistic by one-way ANOVA. Note the C3 results were previously published [165]
} 


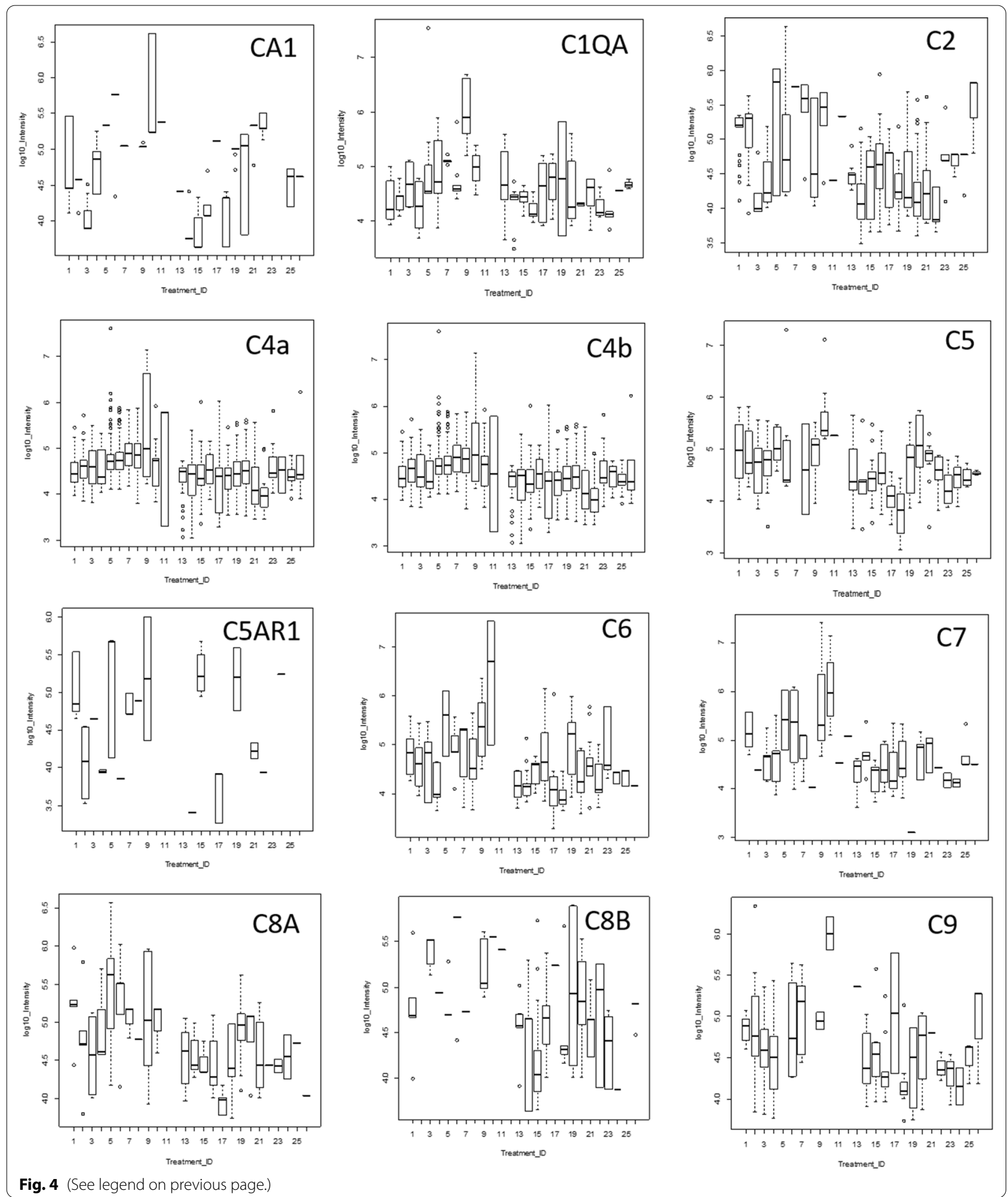




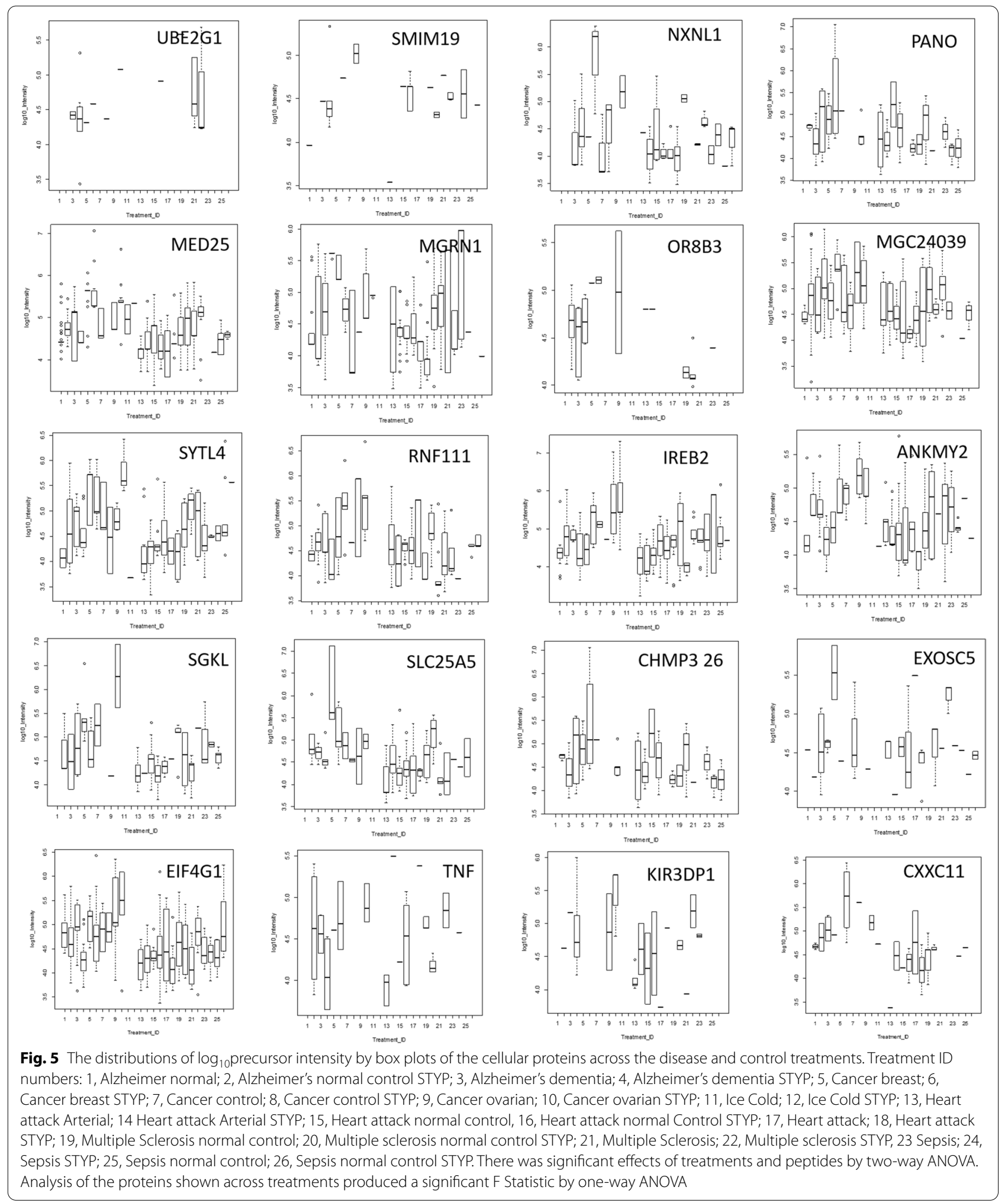




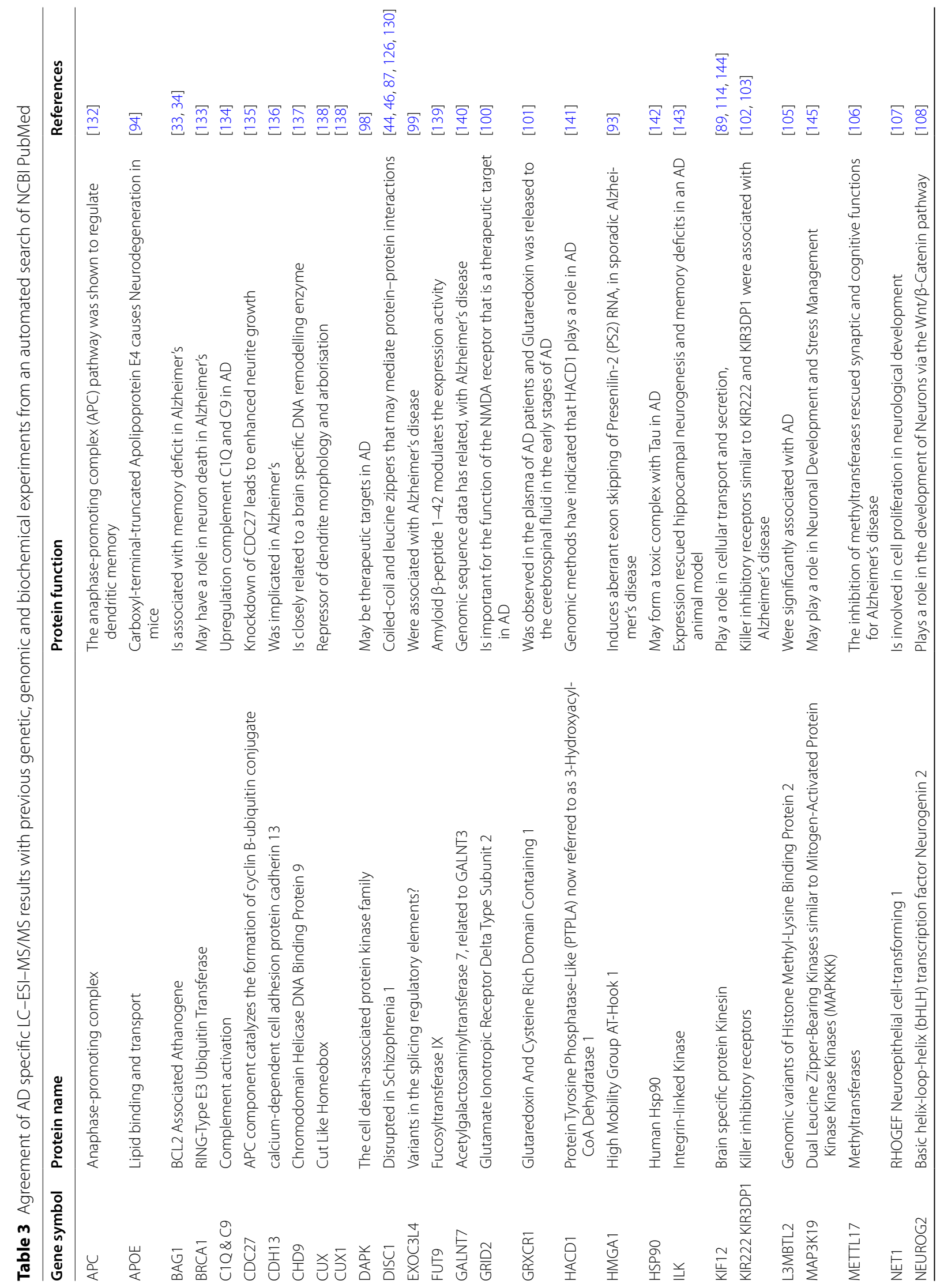




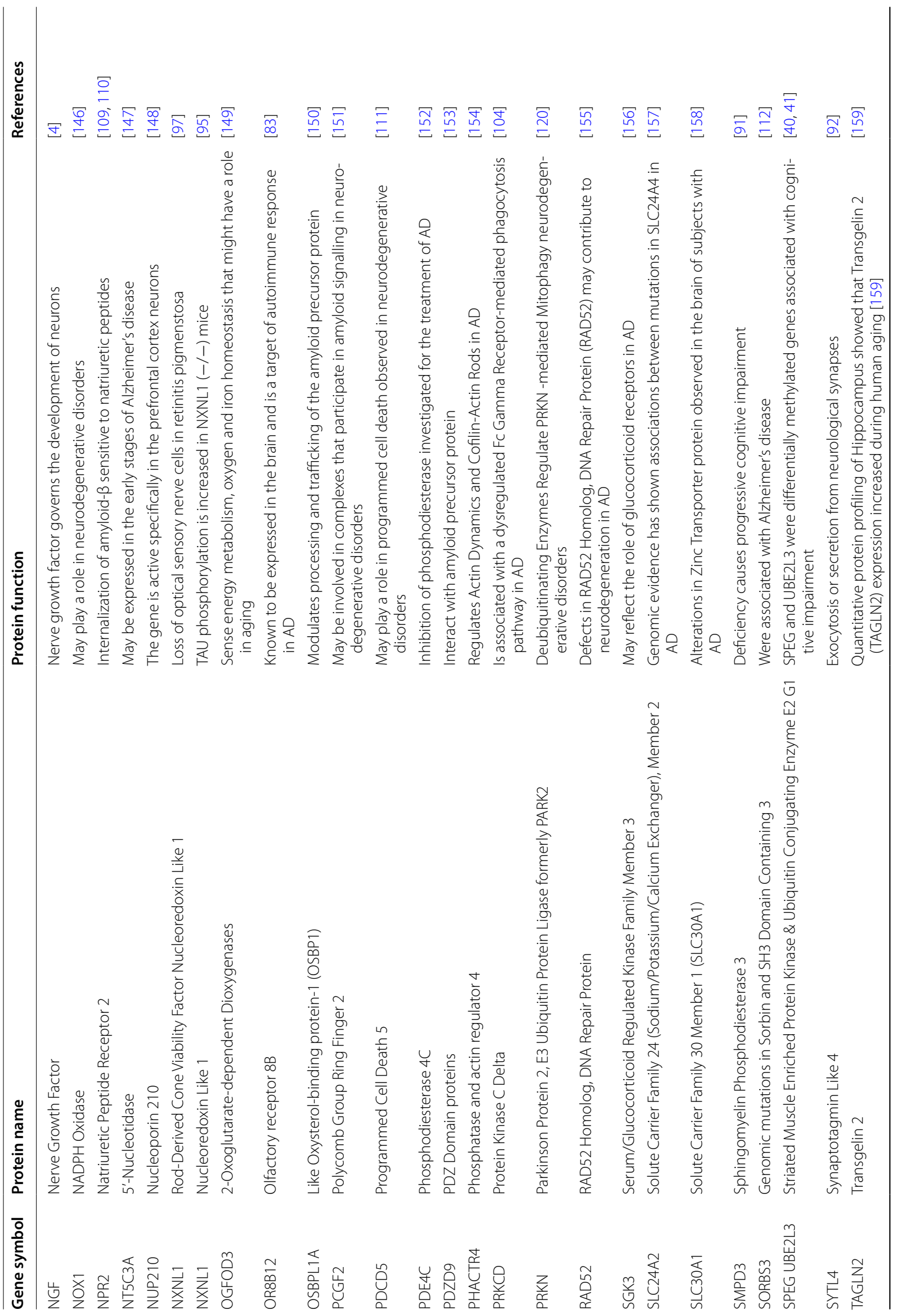




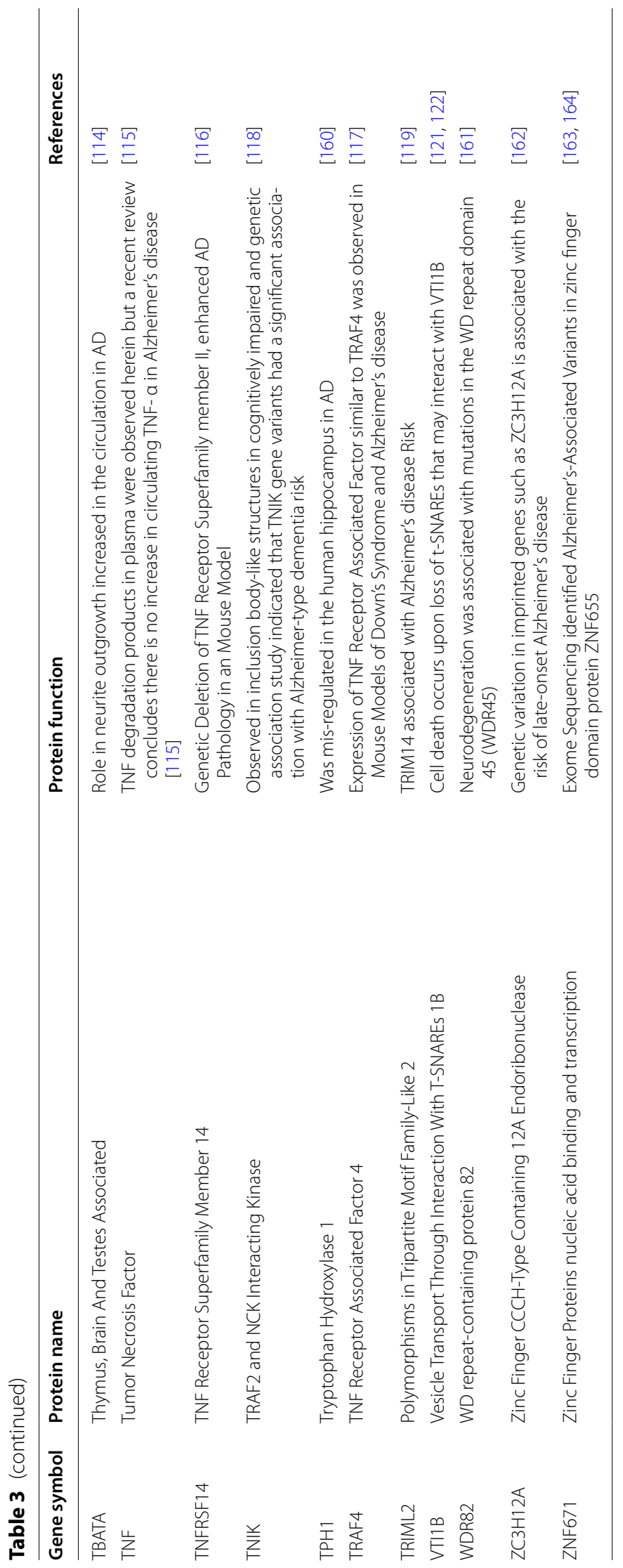



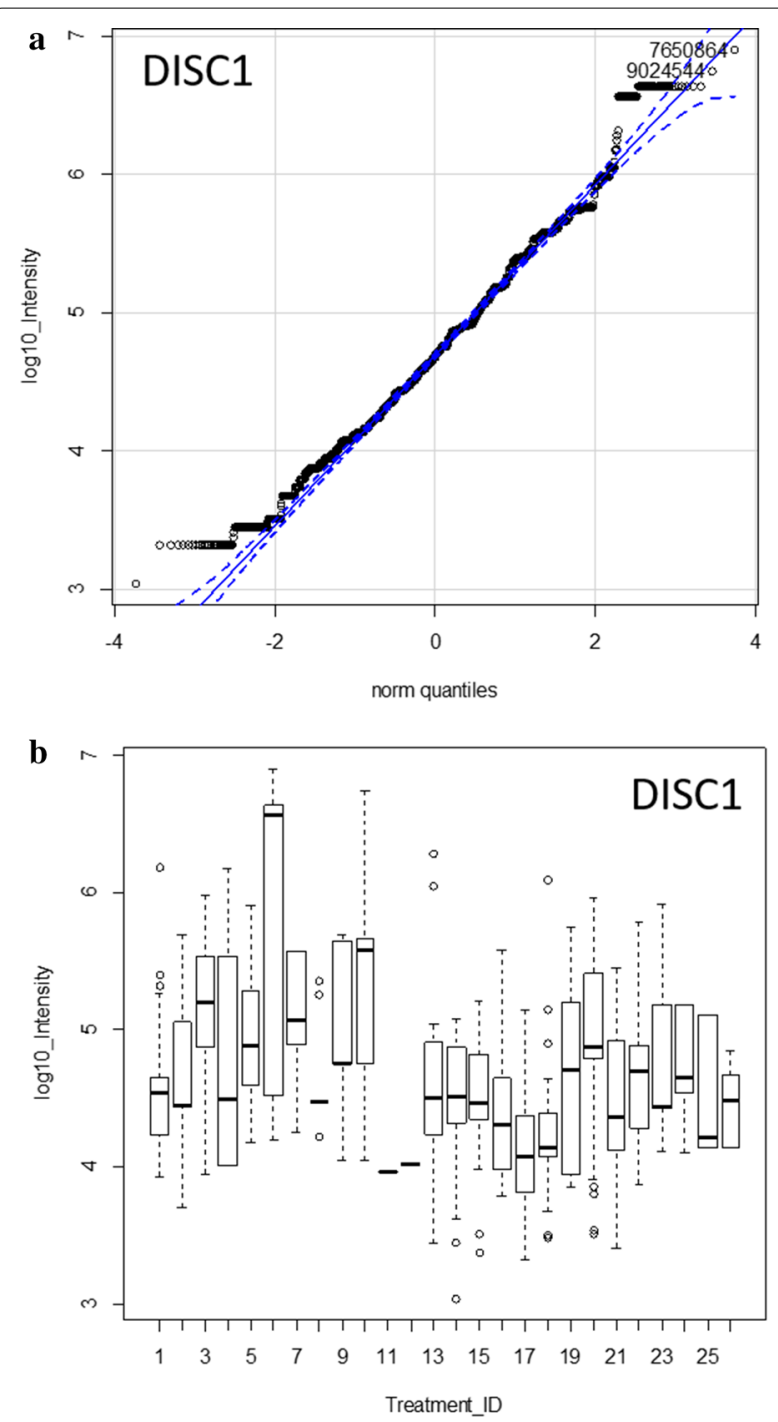

Fig. 6 The quantile and box plot of all DISC1 peptides compared over disease treatments. Panels: a quantile plot showing the Gaussian intensity distribution; $\mathbf{b}$ the quantile box plot showing the intensity distribution of each treatment. Treatment ID numbers: 1, Alzheimer normal; 2, Alzheimer's normal control STYP; 3, Alzheimer's dementia; 4, Alzheimer's dementia STYP; 5, Cancer breast; 6, Cancer breast STYP; 7, Cancer control; 8, Cancer control STYP; 9, Cancer ovarian; 10, Cancer ovarian STYP; 11, Ice Cold; 12, Ice Cold STYP; 13, Heart attack Arterial; 14 Heart attack Arterial STYP; 15, Heart attack normal control, 16, Heart attack normal Control STYP; 17, Heart attack; 18, Heart attack STYP; 19, Multiple Sclerosis normal control; 20, Multiple Sclerosis normal control STYP; 21, Multiple sclerosis; 22, Multiple sclerosis STYP, 23 Sepsis; 24, Sepsis STYP; 25, Sepsis normal control; 26, Sepsis normal control STYP. There was significant effects of treatments and peptides by one way and two-way ANOVA

secretion and signalling proteins associated with regulating cell survival and cell cycle as well as innate immune response and the cell-death, i.e. apoptotic, necrotic, necroptic and/or phagocytic pathways were observed with Alzheimer's dementia [89].

\section{STRING analysis}

Analysis of the proteins frequently observed from endogenous peptides in $\mathrm{AD}$ versus control clinical sample sets using Chi Square analysis was a direct means to look for factors specific to $\mathrm{AD}$ that might play a role in the mechanism of AD pathology for analysis by the STRING algorithm [86]. The large number of edge connections between the gene symbols specific to $\mathrm{AD}$ indicated the proteins observed were not a random assemblage of factors but show biological and protein- interactions consistent with bone fide biological variation between the $A D$ versus $A D$ control treatments. The observed proteins associated with alternate splicing, exocytosis of luminal proteins, and the regulation of the cell survival, mitochondrial functions or metabolism including the metabolism of ceramides [90] and apoptosis were consistent with the known mechanisms of AD pathology described below.

\section{$A D$ versus $A D$ control alongside other diseases and control by ANOVA}

Proteins that showed increased observation frequency in $A D$ versus $A D$ control by Chi Square $\left(\chi^{2}\right)$ were also then analyzed across all disease and control treatments by box plots, quantile plots and ANOVA. The complete analysis of mean precursor intensity [62-64] may require two way ANOVA [61]. Examining the gene symbol intensity across all twelve disease and control clinical sample sets by box plots and two-way ANOVA was a direct means to compare across all other diseases and controls to look for proteins specific to AD. Many of the proteins that show increased observation in AD independently showed greater $\log _{10}$ intensity values that was consistent with true-positive variation between $\mathrm{AD}$ and $\mathrm{AD}$ control. Analysis of peptides across all treatments will be required to extract all of the information from such as large dataset and will require large and automated computations.

\section{Agreement with previous genetic and biochemical experiments}

There was excellent agreement between the proteins observed in the plasma of AD patients and the previous genetic and biochemical evidence for the mechanisms of Alzheimer's dementia at all cellular levels from transporters, receptors, cellular metabolic and signalling enzymes, transcription factors and DNA/RNA binding factors in the results. For example, Sphingomyelin Phosphodiesterase 3 (SMPD3) deficiency causes progressive cognitive 

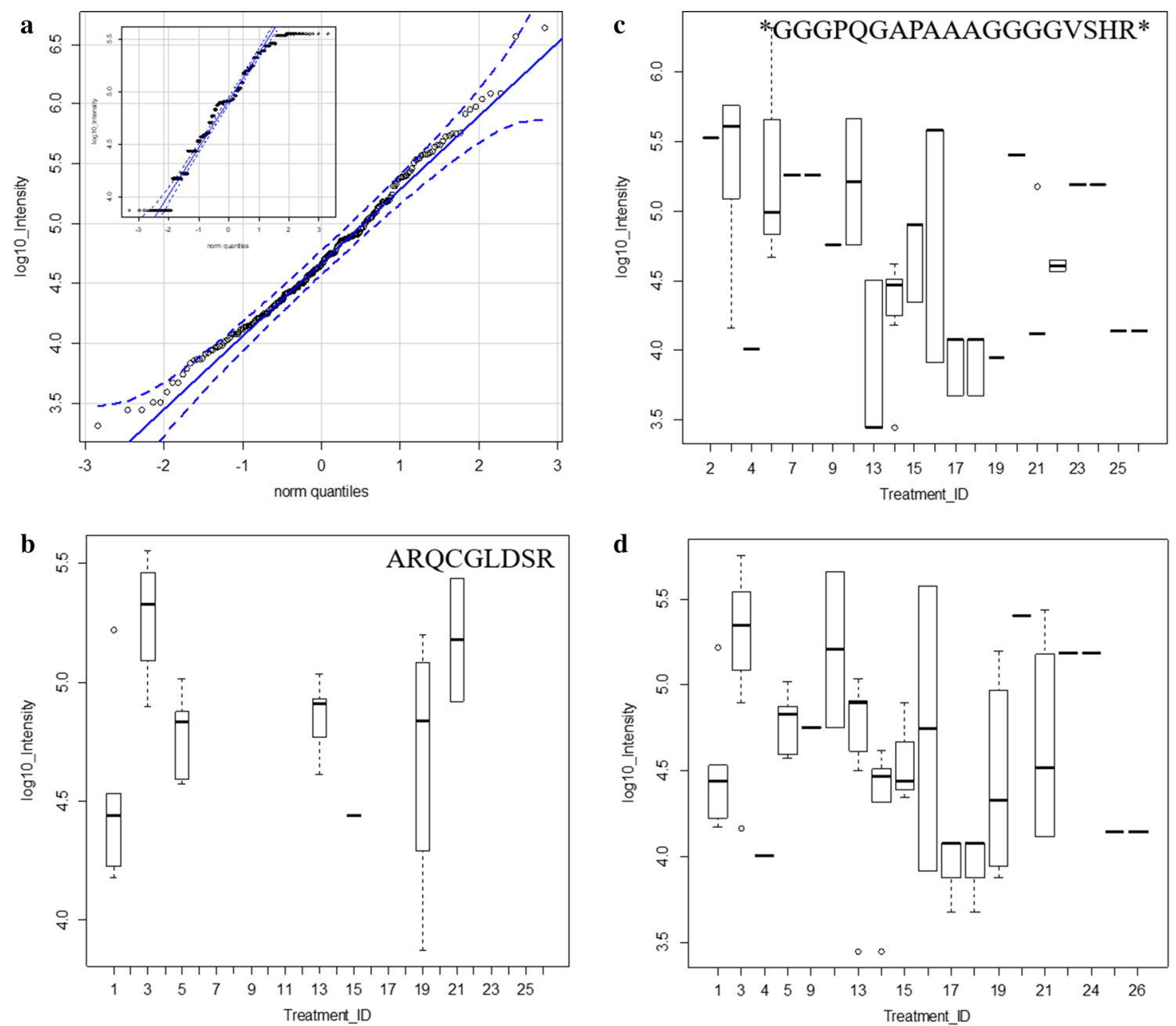

Fig. 7 The intensity distributions of the peptides from the conserved N terminus of DISC1 across disease and controls treatments. Panels: a The quantile plot of all DISC1 peptide intensity from within the sequence MPGGGPQGAPAAAGGGGVSHRAGSRDCLPPAACFR (inset, the quantile plot of the selected DISC1 peptides ARQCGLDS; $\mathbf{b}$ the quantile box plot of the DISC1 peptide ARQCGLDS; $\mathbf{c}$ the quantile box plot of the DISC1 peptides within the sequence MPGGGPQGAPAAAGGGGVSHRAGSRDCLPPAACFR; $\mathbf{d}$ the quantile box plot of the DISC1 peptides from ARQCGLDS and within the sequence MPGGGPQGAPAAAGGGGVSHRAGSRDCLPPAACFR. Treatment ID numbers: 1, Alzheimer normal; 2, Alzheimer's normal control STYP; 3, Alzheimer's dementia; 4, Alzheimer's dementia STYP; 5, Cancer breast; 6, Cancer breast STYP; 7, Cancer control; 8, Cancer control STYP; 9, Cancer ovarian; 10, Cancer ovarian STYP; 11, Ice Cold; 12, Ice Cold STYP; 13, Heart attack Arterial; 14 Heart attack Arterial STYP; 15, Heart attack normal control, 16, Heart attack normal Control STYP; 17, Heart attack; 18, Heart attack STYP; 19, Multiple Sclerosis normal control; 20, Multiple Sclerosis normal control STYP; 21, Multiple sclerosis; 22, Multiple sclerosis STYP, 23 Sepsis; 24, Sepsis STYP; 25, Sepsis normal control; 26, Sepsis normal control STYP. There was significant effects of treatments and peptides by two-way ANOVA

impairment [91]. Synaptotagmin Like 4 (SYTL4) functions in exocytosis or secretion from neurological synapses and so synaptotagmins may be considered as possible $\mathrm{AD}$ biomarkers [92]. Many proteins showed known connections to the mechanisms of AD pathology such as amyloid or Tau pathways including secretases and presenilin. For example HMGA1 induces aberrant exon skipping of Presenilin-2 (PS2) RNA, in sporadic Alzheimer's disease [93]. A chymotrypsin like activity results in a carboxyl-terminal-truncated Apolipoprotein E4 that causes Alzheimer's
disease-Like Neurodegeneration in mice [94]. TAU phosphorylation is increased in Nucleoredoxin Like 1 (NXNL1) $(-/-)$ mice [95]. In contrast, the role of SMIM19 and many other proteins remain entirely obscure with respect to $\mathrm{AD}$.

However, a subset of the AD-specific proteins that were directly related to the cell proliferation, death/ survival and cell clearance pathways will be emphasized here. Nerve growth factor governs the growth 
Table 4 The analysis of $\log _{10}$ peptide intensity DISC1 protein by ANOVA from all DISC1 (NP_001158009) peptides and from the selected peptides ARQCGLDS \& MPGGGPQ* for means comparison

\begin{tabular}{|c|c|c|c|c|c|c|}
\hline Treatment_ID & $\begin{array}{l}\text { Log10 Intensity } \\
\text { All Peptides }\end{array}$ & se & $\mathrm{N}$ & $\begin{array}{l}\text { Log10 intensity } \\
\text { ARQCGLDS \& MPGGGPQ* }\end{array}$ & se & $\mathrm{N}$ \\
\hline 1 & 4.54 & 0.12 & 13 & 4.52 & 0.19 & 5 \\
\hline 2 & 4.64 & 0.16 & 10 & NA & NA & NA \\
\hline 3 & 5.14 & 0.09 & 28 & 5.27 & 0.10 & 16 \\
\hline 4 & 4.52 & 0.21 & 7 & 4.01 & NA & 1 \\
\hline 5 & 5.03 & 0.14 & 8 & 4.78 & 0.09 & 5 \\
\hline 6 & 5.48 & 0.65 & 4 & NA & NA & NA \\
\hline 7 & 5.07 & 0.18 & 4 & NA & NA & NA \\
\hline 8 & 4.47 & NA & 1 & NA & NA & NA \\
\hline 9 & 4.97 & 0.20 & 7 & 4.75 & 0.00 & 2 \\
\hline 10 & 5.47 & 0.13 & 10 & 5.21 & 0.26 & 4 \\
\hline 13 & 4.47 & 0.13 & 20 & 4.67 & 0.16 & 9 \\
\hline 14 & 4.58 & 0.15 & 10 & 4.27 & 0.21 & 5 \\
\hline 15 & 4.43 & 0.10 & 14 & 4.56 & 0.17 & 3 \\
\hline 16 & 4.42 & 0.19 & 8 & 4.75 & 0.83 & 2 \\
\hline 17 & 4.10 & 0.16 & 10 & 3.94 & 0.13 & 3 \\
\hline 18 & 4.65 & 0.25 & 11 & 3.94 & 0.13 & 3 \\
\hline 19 & 4.57 & 0.18 & 10 & 4.44 & 0.24 & 6 \\
\hline 20 & 4.81 & 0.28 & 6 & 5.40 & 0.00 & 2 \\
\hline 21 & 4.54 & 0.17 & 10 & 4.65 & 0.32 & 4 \\
\hline 22 & 4.62 & 0.14 & 8 & NA & NA & NA \\
\hline 23 & 4.79 & 0.21 & 8 & 5.18 & 0.00 & 2 \\
\hline 24 & 4.73 & 0.16 & 6 & 5.18 & 0.00 & 2 \\
\hline 25 & 4.47 & 0.22 & 4 & 4.14 & NA & 1 \\
\hline 26 & 4.41 & 0.27 & 2 & 4.14 & NA & 1 \\
\hline
\end{tabular}

Treatment ID numbers: 1, Alzheimer normal; 2, Alzheimer's normal control STYP; 3, Alzheimer's dementia; 4, Alzheimer's dementia STYP; 5, Cancer breast; 6, Cancer breast STYP; 7, Cancer control; 8, Cancer control STYP; 9, Cancer ovarian; 10, Cancer ovarian STYP; 11, Ice Cold; 12, Ice Cold STYP; 13 , Heart attack Arterial; 14 Heart attack Arterial STYP; 15, Heart attack normal control, 16, Heart attack normal Control STYP; 17, Heart attack; 18, Heart attack STYP; 19, Multiple Sclerosis normal control; 20, Multiple sclerosis normal control STYP; 21, Multiple sclerosis; 22, Multiple Sclerosis STYP, 23 Sepsis; 24, Sepsis STYP; 25, Sepsis normal control; 26, Sepsis normal control STYP

development of neurons [4]. The ataxia-telangiectasia mutated (ATM) protein kinase is associated with neurodegeneration and is a master regulator of the DNA damage response that may be activated by Nibrin, i.e. NBS1(NBN) [96]. The Rod-Derived Cone Viability Factor Nucleoredoxin Like 1 (NXNL1) that governs the loss of optical sensory nerve cells in retinitis pigmenstosa has a direct connection to the regulation of cell death [97]. The cell death-associated protein kinase family (DAPK) may be therapeutic targets [98]. Variants in the splicing regulatory elements of EXOC3L4 were associated with Alzheimer's disease [99]. GRID2 is important for the function of the NMDA receptor that plays a key role in synaptogenesis, synaptic plasticity, and motor coordination and that is a therapeutic target in AD [100]. Glutaredoxin And Cysteine Rich Domain Containing 1 (GRXCR1) that may function in cell survival was observed in the plasma of AD patients and Glutaredoxin was released to the cerebrospinal fluid in the early stages of AD [101]. Killer inhibitory receptors similar to KIR222 and KIR3DP1 that may function in cell clearance were associated with Alzheimer's disease $[102,103]$. Protein Kinase C Delta (PRKCD) is associated with a dysregulated Fc Gamma Receptor-mediated phagocytosis pathway in Alzheimer's disease [104]. Genomic variants of Histone Methyl-Lysine Binding Protein 2 (L3MBTL2) that may function in the survival of motor neurons were significantly associated with $\mathrm{AD}$ [105]. The inhibition of methyltransferases that are functionally or structurally related to METTL17 rescued synaptic and cognitive functions for Alzheimer's disease [106]. The RHOGEF Neuroepithelial cell-transforming 1 (NET1) is involved in cell proliferation in neurological development [107]. The basic helix-loophelix (bHLH) transcription factor Neurogenin 2 (NEUROG2) plays a role in the development of Neurons via the Wnt/ $\beta$-Catenin pathway [108]. The observed changes in Natriuretic Peptide Receptor 2 (NPR2) may 


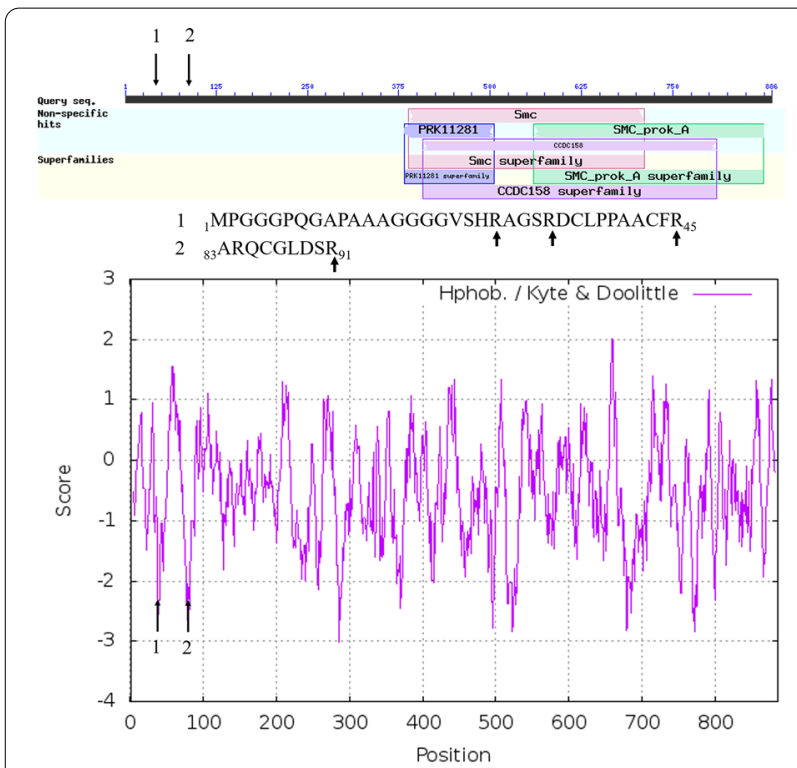

Fig. 8 The primary structure and hydrophobicity plot of Disrupted in Schizophrenia 1 protein isoform a [Homo sapiens] DISC1 NP_001158009.1. The long arrow shows the cleavage site of the tryptic peptides sequences: 1, MPGGGPQGAPAAAGGG GVSHRAGSRDCLPPAACFR 4 ; ; and 2, ${ }_{83}$ ARQCGLDSR $_{91}$ from the conserved and unique $\mathrm{C}$-terminal domain of DISC1 that is conserved within humans and across mammals in sequences available to date. The short arrows show the location of the tryptic cleavage sites observed

reflect the internalization of amyloid- $\beta$ Peptide in brain capillary endothelial cells $[109,110]$. Molecules like Programmed Cell Death 5 (PDCD5) may play a role in programmed cell death observed in neurodegenerative disorders [111]. Genomic mutations in Sorbin and SH3 Domain Containing 3 (SORBS3) that may regulate cell proliferation were associated with Alzheimer's disease [112, 113]. Thymus, Brain And Testes Associated (TBATA) that plays a role in neurite outgrowth increased in the circulation in AD [114]. Greater levels of TNF degradation products in plasma were observed herein but a recent review concludes there is no increase in circulating TNF- $\alpha$ in Alzheimer's disease [115] perhaps indicating a role for turnover in the regulation of TNF levels. Genetic Deletion of TNF Receptor Superfamily member II, that is functionally similar to TNFRSF14, enhanced the Alzheimer-like Pathology in an APP Transgenic Mouse Model [116]. Expression of TNF Receptor Associated Factor similar to TRAF4 was observed in mouse Models of Down's Syndrome and Alzheimer's disease [117]. TRAF2 and NCK Interacting Kinase (TNIK) was observed in inclusion body-like structures in cognitively impaired and genetic association study indicated that TNIK gene variants had a significant association with Alzheimertype dementia risk [118]. The tripartite motif (TRIM) proteins, characterized by the RING, B-Box and coiledcoil (RBCC) domains at the $\mathrm{N}$-terminus, interact with p53 to regulate cell proliferation/death and polymorphisms in Tripartite Motif Family-Like 2 (TRIML2) that is structurally or functionally similar to TRIM14 were associated with Alzheimer's disease Risk [119]. Deubiquitinating Enzymes Regulate PARK2-mediated Mitophagy is implicated in many neurodegenerative disorders like Alzheimer's disease [120]. Presenilin controls kinesin-1 and dynein function during APP-vesicle Transport in vivo and cell death occurs upon loss of t-SNAREs $[121,122]$ that may interact with protein such as Vesicle Transport through Interaction with T-SNAREs 1B (VTI1B).

\section{Structure and functions of DISC1}

The DISC1 gene that is disrupted in schizophrenia encodes coiled-coil domain protein conserved in bacteria and eukaryotes that functions in chromosome segregation and structural maintenance of chromosomes with homology to SMC and SMC_prok_A domains that may localize to the centrosome and punctate cytoplasmic foci and is classified as a scaffold protein due to its established interactions with several other proteins including AA598854 activating transcription factors 4 and 5 (ATF4 and ATF5) and Microtubule Associated Protein 1A (MAP1A) [123], Platelet Activating Factor Acetylhydrolase 1b Regulatory Subunit 1 (PAFAH1B1), Pericentrin (PCNT) [124, 125] and Interaction with NudE Neurodevelopment Protein 1 Like 1 (NDEL1) [126, 127]. DISC1 is involved in neurogenesis that is regulated by WNT signalling leading to neural progenitor proliferation by modulating GSK3B activity and CTNNB1 abundance $[128,129]$ and inhibits AKT-mTOR upon interaction with CCDC88A [130, 131].

Table 5 The conserved domains of DISC1 (NP_001158009) from NCBI BLAST analysis and Domain Architecture retrieval tool (DART)

\begin{tabular}{lllcc}
\hline Name & Accession & Description & Interval & E-value \\
\hline SmC & COG1196 & Chromosome segregation ATPase, Cell cycle control, cell division & $388-711$ & $1.25 E-05$ \\
PRK11281 & PRK11281 & Mechanosensitive channel MsCK & $382-506$ & 0.000816 \\
SMC_prok_A & TIGR02169 & Chromosome segregation protein SMC, primarily archaeal type & $559-874$ & 0.00211 \\
CCDC158 & pfam15921 & Coiled-coil domain-containing protein 158, CCDC158 & $408-810$ & 0.00274 \\
\hline
\end{tabular}


The apparent functions of DISC1 in regulating genomic organization and gene expression that may influence neuronal development are consistent with the variation in DISC1 peptides observed in Alzheimer's dementia. Thus, it might be possible to detect and resolve $\mathrm{AD}$ patients from the background population of $\mathrm{AD}$ controls by monitoring the levels and/or processing of DISC1 in EDTA plasma.

\section{Conclusion}

It was possible to discover peptides and/or proteins that showed variation specific to $A D$ versus other diseases, or normal plasma samples, from many institutions using disposable sample preparation, common bench-top instrumentation, and generic computation. The LC-ESIMS/MS of plasma endogenous tryptic peptides identified many blood proteins and/or peptides in $A D$ versus $A D$ control that were previously associated with the innate immune response. The observation frequency and intensity of proteins specific to AD agreed with STRING analysis of known interactions and the previous genetic and biochemical evidence that the peptides and proteins specific to AD showed statistical and biological significance with respect to marking the mechanisms of the disease process including aberrant RNA metabolism. Cleavage of the DISC1 protein to release peptides from the $\mathrm{COOH}$ terminal and elsewhere was more frequent in $\mathrm{AD}$ compared to all other diseases and controls. DISC1 peptides discovered by random and independent sampling of test samples might be confirmed by automatic targeted LCESI-MS/MS [49, 65, 82] from a larger cohort of independent samples.

\section{Abbreviations}

AD: Alzheimer's Disease; TRYP: Fully tryptic; STYP: S, T or Y tryptic phosphopeptide and/or fully tryptic

\section{Supplementary Information}

The online version contains supplementary material available at https://doi. org/10.1186/s12014-021-09320-2.

Additional file 1: Table S1. The list of protein Gene Symbols with Chi Square (X2) values greater than nine (9) at 1 degree of freedom.

Additional file 2: Table S2. The STRING Keyword analysis with Chi Square (X2) values greater than nine (9) at 1 degree of freedom.

Additional file 3: Table S3. The STRING Component analysis with Chi Square ( $X 2)$ values greater than nine (9) at 1 degree of freedom.

Additional file 4: Table S4. The STRING Function analysis with Chi Square (X2) values greater than nine (9) at 1 degree of freedom.

Additional file 5: Table S5. The STRING Process analysis with Chi Square (X2) values greater than nine (9) at 1 degree of freedom.

Additional file 6: Table S6. The replication of the LC-ESI-MS/MS experiments.

\section{Acknowledgements}

We thank Dr. R.A. Phillips for his long running support for this program of research, his aid in obtaining human normal and cancer controls and his help and opinions in the preparation of the manuscript.

\section{Authors' contributions}

AFM prepared samples and performed LC-ESI-MS/MS analysis. PB performed the X!TANDEM, SEQUEST and SQL Server analysis of the LC-ESI-MS/MS data. PS, planned the study, created the sampling scheme and collected the samples. JK, planned the study, created the sampling scheme and collected the samples. CT planned the study, conceived the study, created the sampling scheme, biobanked and provided the blinded samples and revealed the blind. JGM, planned the study, wrote grants in support of the study, performed the $R$ statistical analysis and wrote the manuscript. All authors read and approved the final manuscript.

\section{Funding}

Funding to develop the SQL SERVER-R computation platform, and to sample the breast and ovarian cancer samples, provided by the Ontario Institute of Cancer Research through the Ontario Cancer Biomarker Network to JGM.

The funding to create the reference control samples and sample the AD and MS plasma and controls was from Fonds National de la Recherche, through Luxembourg Institute of Health LIH (formerly CRP Sante) and the Integrated Biobank of Luxembourg (IBBL) to JGM. The heart attack results were collected using funding from the Heart and Stroke Foundation of Ontario and Canada to JGM. Funding for wet lab and LC-ESI-MS/MS instruments and for sampling Sepsis was from the Natural Science and Engineering Research Council of Canada (NSERC) CRD Grant with YYZ PHARMATECH to JGM.

\section{Availability of data and materials}

The raw data is provided in companion publication and the supplemental data.

\section{Declarations}

Ethics approval and consent to participate

Human EDTA plasma samples were obtained under Ryerson Ethical Reviews Board Protocol REB 2015-207.

\section{Consent for publication}

No original figures or tables from any other publisher were reproduced in this publication.

\section{Competing interests}

The authors declare that they have no competing interests.

\section{Author details}

${ }^{1}$ Ryerson Analytical Biochemistry Laboratory (RABL), Department of Chemistry and Biology, Faculty of Science, Ryerson University, 350 Victoria St., Toronto, ON, Canada. ${ }^{2}$ Alzheimer Center, Dept of Neurology, Amsterdam University Medical Centers, Vrije Universiteit, Amsterdam Neuroscience, Amsterdam, The Netherlands. ${ }^{3}$ MS Center, Dept of Neurology, Amsterdam University Medical Centers, Vrije Universiteit, Amsterdam Neuroscience, Amsterdam, The Netherlands. ${ }^{4}$ Neurochemistry Lab and Biobank, Dept of Clinical Chemistry, Amsterdam University Medical Centers, Vrije Universiteit, Amsterdam Neuroscience, Amsterdam, The Netherlands. ${ }^{5}$ International Biobank of Luxembourg (IBBL), Luxembourg Institute of Health (Formerly CRP Sante Luxembourg), Strassen, Luxembourg.

Received: 25 January 2021 Accepted: 20 April 2021

Published online: 28 June 2021

\section{References}

1. Khan AT, et al. Alzheimer's disease: are blood and brain markers related? A systematic review. Ann Clin Transl Neurol. 2016;3(6):455-62.

2. Biamonti $G$, et al. Alternative splicing in Alzheimer's disease. Aging Clin Exp Res. 2019;33:747-758 
3. Love JE, Hayden EJ, Rohn TT. Alternative splicing in Alzheimer's Disease. J Parkinsons Dis Alzheimers Dis. 2015;2(2):6.

4. Cuello AC, Pentz R, Hall H. The brain NGF metabolic pathway in health and in Alzheimer's Pathology. Front Neurosci. 2019;13:62.

5. Malekzadeh A, et al. Plasma proteome in multiple sclerosis disease progression. Ann Clin Transl Neurol. 2019;6(9):1582-94.

6. Abe $\mathrm{K}$, et al. A new serum biomarker set to detect mild cognitive impairment and Alzheimer's disease by peptidome technology. J Alzheimers Dis. 2020;73(1):217-27.

7. Gamez-Valero A, et al. Comprehensive proteomic profiling of plasmaderived Extracellular Vesicles from dementia with Lewy Bodies patients. Sci Rep. 2019;9(1):13282.

8. Tucholska $\mathrm{M}$, et al. Endogenous peptides from biophysical and biochemical fractionation of serum analyzed by matrix-assisted laser desorption/ionization and electrospray ionization hybrid quadrupole time-of-flight. Anal Biochem. 2007;370:228-45.

9. Fania $\mathrm{C}$, et al. Protein signature in cerebrospinal fluid and serum of $\mathrm{Alz}$ heimer's disease patients: the case of apolipoprotein A-1 proteoforms. PLoS One. 2017;12(6):e0179280.

10. Song $F$, et al. Plasma protein profiling of Mild Cognitive Impairment and Alzheimer's disease using iTRAQ quantitative proteomics. Proteome Sci. 2014;12(1):5.

11. Oeckl P, et al. Targeted mass spectrometry suggests beta-synuclein as synaptic blood marker in Alzheimer's Disease. J Proteome Res. 2020;19(3):1310-8.

12. Harris $\mathrm{SE}$, et al. Neurology-related protein biomarkers are associated with cognitive ability and brain volume in older age. Nat Commun. 2020;11(1):800.

13. Shi L, et al. Discovery and validation of plasma proteomic biomarkers relating to brain amyloid burden by SOMAscan assay. Alzheimers Dement. 2019:15(11):1478-88

14. Westwood S, et al. Validation of plasma proteomic biomarkers relating to brain amyloid burden in the EMIF-Alzheimer's disease multimodal biomarker discovery cohort. J Alzheimers Dis. 2020;74(1):213-25.

15. Cooper JD, et al. Schizophrenia-risk and urban birth are associated with proteomic changes in neonatal dried blood spots. Transl Psychiatry. 2017;7(12):1290

16. Brouwers $\mathrm{N}$, et al. Alzheimer risk associated with a copy number variation in the complement receptor 1 increasing $\mathrm{C} 3 \mathrm{~b} / \mathrm{C} 4 \mathrm{~b}$ binding sites. Mol Psychiatry. 2012;17(2):223-33.

17. Vanguri $P$, et al. Complement activation by isolated myelin: activation of the classical pathway in the absence of myelin-specific antibodies. Proc Natl Acad Sci U S A. 1982;79(10):3290-4.

18. Ingram $\mathrm{G}$, et al. Elevated plasma $\mathrm{C} 4 \mathrm{a}$ levels in multiple sclerosis correlate with disease activity. J Neuroimmunol. 2010;223(1-2):124-7.

19. Bennett $S$, et al. Plasma levels of complement $4 a$ protein are increased in Alzheimer's disease. Alzheimer Dis Assoc Disord. 2012;26(4):329-34.

20. Walss-Bass C, et al. X-Aptamer technology identifies C4A and ApoB in blood as potential markers for schizophrenia. Mol Neuropsychiatry. 2019:5(1):52-9.

21. Hong S, et al. Complement and microglia mediate early synapse loss in Alzheimer mouse models. Science. 2016;352(6286):712-6.

22. Goetzl EJ, et al. High complement levels in astrocyte-derived exosomes of Alzheimer disease. Ann Neurol. 2018;83(3):544-52.

23. Winston CN, et al. Complement protein levels in plasma astrocytederived exosomes are abnormal in conversion from mild cognitive impairment to Alzheimer's disease dementia. Alzheimers Dement (Amst). 2019;11:61-6.

24. Fountoulakis M, Cairns N, Lubec G. Increased levels of 14-3-3 gamma and epsilon proteins in brain of patients with Alzheimer's disease and Down syndrome. J Neural Transm Suppl. 1999;57:323-35.

25. Syed $P$, et al. Autoantibody profiling of glioma serum samples to identify biomarkers using human proteome arrays. Sci Rep. 2015;5:13895.

26. Lim B, et al. Putative autoantibodies in the cerebrospinal fluid of Alzheimer's disease patients. F1000Res. 2019;8:1900.

27. Baek $\mathrm{H}$, et al. Neuroprotective effects of $\mathrm{CD} 4+\mathrm{CD} 25+$ Foxp3+ regulatory T cells in a 3xTg-AD Alzheimer's disease model. Oncotarget. 2016;7(43):69347-57.

28. Iuliano $\mathrm{O}$, et al. Myosin $1 \mathrm{~b}$ promotes axon formation by regulating actin wave propagation and growth cone dynamics. J Cell Biol. 2018;217(6):2033-46.
29. Hibar DP, et al. Novel genetic loci associated with hippocampal volume. Nat Commun. 2017:8:13624.

30. Rocchi A, et al. A Becn1 mutation mediates hyperactive autophagic sequestration of amyloid oligomers and improved cognition in Alzheimer's disease. PLoS Genet. 2017;13(8):e1006962.

31. Hondius DC, et al. Profiling the human hippocampal proteome at all pathologic stages of Alzheimer's disease. Alzheimers Dement. 2016;12(6):654-68.

32. Blanken $A E$, et al. Associations between hippocampal morphometry and neuropathologic markers of Alzheimer's disease using 7 T MRI. Neuroimage Clin. 2017;15:56-61.

33. Venturelli E, et al. BAG1 is a protective factor for sporadic frontotemporal lobar degeneration but not for Alzheimer's disease. J Alzheimers Dis. 2011;23(4):701-7.

34. Shi Z, et al. BAG-1M co-activates BACE1 transcription through NFkappaB and accelerates Abeta production and memory deficit in Alzheimer's disease mouse model. Biochim Biophys Acta Mol Basis Dis. 2017;1863(9):2398-407.

35. Elliott E, Laufer O, Ginzburg I. BAG-1M is up-regulated in hippocampus of Alzheimer's disease patients and associates with tau and APP proteins. J Neurochem. 2009;109(4):1168-78.

36. Decourt B, Lahiri DK, Sabbagh MN. Targeting tumor necrosis factor alpha for Alzheimer's disease. Curr Alzheimer Res. 2017;14(4):412-25.

37. Chang $R$, et al. Blood-brain barrier penetrating biologic TNF-alpha Inhibitor for Alzheimer's disease. Mol Pharm. 2017;14(7):2340-9.

38. Mitra S, Behbahani H, Eriksdotter M. Innovative therapy for Alzheimer's disease-with focus on biodelivery of NGF. Front Neurosci. 2019;13:38.

39. Tuszynski MH, et al. Nerve growth factor gene therapy: activation of neuronal responses in Alzheimer disease. JAMA Neurol. 2015;72(10):1139-47.

40. Pathak GA, et al. Genome-wide methylation of mild cognitive impairment in mexican Americans highlights genes involved in synaptic transport, Alzheimer's disease-precursor phenotypes, and metabolic morbidities. J Alzheimers Dis. 2019;72(3):733-49.

41. Lim KH, Joo JY. Predictive potential of circulating Ube2h mRNA as an E2 ubiquitin-conjugating enzyme for diagnosis or treatment of Alzheimer's disease. Int J Mol Sci. 2020;21(9):3398.

42. Ayalew $\mathrm{M}$, et al. Convergent functional genomics of schizophrenia: from comprehensive understanding to genetic risk prediction. Mol Psychiatry. 2012;17(9):887-905.

43. Millar JK, et al. Disruption of two novel genes by a translocation cosegregating with schizophrenia. Hum Mol Genet. 2000;9(9):1415-23.

44. Shahani N, et al. DISC1 regulates trafficking and processing of APP and Abeta generation. Mol Psychiatry. 2015;20(7):874-9.

45. Wang ZT, et al. Disrupted-in-schizophrenia-1 protects synaptic plasticity in a transgenic mouse model of Alzheimer's disease as a mitophagy receptor. Aging Cell. 2019;18(1):e12860.

46. Zhang XY, et al. Association of DISC1 polymorphisms with lateonset Alzheimer's disease in northern han Chinese. Mol Neurobiol. 2017;54(4):2922-7.

47. Deng QS, et al. Disrupted-in-schizophrenia-1 attenuates amyloid-beta generation and cognitive deficits in APP/PS1 transgenic mice by reduction of beta-site APP-cleaving enzyme 1 levels. Neuropsychopharmacology. 2016;41(2):440-53.

48. Thavarajah $\mathrm{T}$, et al. Re-evaluation of the 18 non-human protein standards used to create the Empirical Statistical Model for Decoy Library Searching. Anal Biochem. 2020;599:113680.

49. Dufresne J, et al. Random and independent sampling of endogenous tryptic peptides from normal human EDTA plasma by liquid chromatography micro electrospray ionization and tandem mass spectrometry. Clin Proteomics. 2017;14:41.

50. Dufresne J, et al. The plasma peptidome. Clin. Proteomics. 2018;15:39.

51. Haverland NA, et al. The proteomic characterization of plasma or serum from HIV-infected patients. Methods Mol Biol. 2016;1354:293-310.

52. Menon R, et al. Quantitative proteomics by SWATH-MS of maternal plasma exosomes determine pathways associated with term and preterm birth. Endocrinology. 2019;160(3):639-50.

53. Miyauchi $\mathrm{E}$, et al. Identification of blood biomarkers in glioblastoma by SWATH mass spectrometry and quantitative targeted absolute proteomics. PLoS One. 2018;13(3):e0193799. 
54. Messner CB, et al. Ultra-High-Throughput Clinical Proteomics Reveals Classifiers of COVID-19 Infection. Cell Syst. 2020;11:11-24.

55. Dufresne J, et al. A method for the extraction of the endogenous tryptic peptides (peptidome) from human EDTA plasma. Anal Biochem. 2018:549:188-196

56. Tucholska M, et al. Human serum proteins fractionated by preparative partition chromatography prior to LC-ESI-MS/MS. J Proteome Res. 2009;8:1143-55

57. Craig R, Beavis RC. TANDEM: matching proteins with tandem mass spectra. Bioinformatics. 2004;20(9):1466-7.

58. Eng JK, McCormack AL, Yates JR. An approach to correlate tandem mass spectral data of peptides with amino acid sequences in a protein database. J Am Soc Mass Spectrom. 1994:5(11):976-89.

59. Patterson SD. Data analysis-the Achilles heel of proteomics. Nat Biotechnol. 2003;21(3):221-2.

60. Bowden P, Beavis R, Marshall J. Tandem mass spectrometry of human tryptic blood peptides calculated by a statistical algorithm and captured by a relational database with exploration by a general statistical analysis system. J Proteomics. 2009;73:103-11.

61. Bowden P, et al. Quantitative statistical analysis of standard and human blood proteins from liquid chromatography, electrospray ionization and tandem mass spectrometry. J Proteome Res. 2012;11:2032-47.

62. Florentinus AK, et al. Identification and quantification of peptides and proteins secreted from prostate epithelial cells by unbiased liquid chromatography tandem mass spectrometry using goodness of fit and analysis of variance. J Proteomics. 2012;75:1303-17.

63. Florentinus $A K$, et al. The Fc receptor-cytoskeleton complex from human neutrophils. J Proteomics. 2011;75:450-68.

64. Marshall J, et al. Processing of serum proteins underlies the mass spectral fingerprinting of myocardial infarction. J Proteome Res. 2003:2:361-72

65. Dufresne J, et al. Freeze-dried plasma proteins are stable at room temperature for at least 1 year. Clin Proteomics. 2017;14:35.

66. Krokhin OV, Ens W, Standing KG. MALDI QqTOF MS combined with off-line HPLC for characterization of protein primary structure and post-translational modifications. J Biomol Tech. 2005;16(4):429-40.

67. Williams D, Zhu P, Bowden P, Stacey C, McDonell M, Kowalski P, Kowalski JM, Evans K, Diamandis EP, Siu KM, Marshall J. Comparison of methods to examine the endogenous peptides of fetal calf serum. Clin Proteomics. 2007;2(1):67-89.

68. Marshall J, et al. Human serum proteins preseparated by electrophoresis or chromatography followed by tandem mass spectrometry. J Proteome Res. 2004;3(3):364-82.

69. Zhu P, et al. Chi-square comparison of tryptic peptide-to-protein distributions of tandem mass spectrometry from blood with those of random expectation. Anal Biochem. 2011;409(2):189-94.

70. Zhu P, et al. Peptide-to-protein distribution versus a competition for significance to estimate error rate in blood protein identification. Anal Biochem. 2011:411:241-53.

71. Schwartz JC, Senko MW, Syka JE. A two-dimensional quadrupole ion trap mass spectrometer. J Am Soc Mass Spectrom. 2002;13(6):659-69.

72. Bowden $P$, et al. Meta sequence analysis of human blood peptides and their parent proteins. J Proteomics. 2010:73:1163-75.

73. Tucholska M, et al. The endogenous peptides of normal human serum extracted from the acetonitrile-insoluble precipitate using modified aqueous buffer with analysis by LC-ESI-Paul ion trap and Qq-TOF. J Proteomics. 2010;73(6):1254-69.

74. Williams $D$, et al. Precipitation and selective extraction of human serum endogenous peptides with analysis by quadrupole time-offlight mass spectrometry reveals posttranslational modifications and low-abundance peptides. Anal Bioanal Chem. 2010;396:1223-47.

75. Zhang Y, et al. Comparison of human glomerulus proteomic profiles obtained from low quantities of samples by different mass spectrometry with the comprehensive database. Proteome Sci. 2011;9(1):47.

76. Yates JR 3rd, et al. Method to correlate tandem mass spectra of modified peptides to amino acid sequences in the protein database. Anal Chem. 1995;67(8):1426-36.

77. Dufresne J, et al. Re-evaluation of the rabbit myosin protein standard used to create the empirical statistical model for decoy library searching. Anal Biochem. 2018;560:39-49.
78. Chick JM, et al. A mass-tolerant database search identifies a large proportion of unassigned spectra in shotgun proteomics as modified peptides. Nat Biotechnol. 2015;33(7):743-9.

79. Kinzel V, Kubler D. Phospho-accepting proteins in bovine sera. Blut. 1976:33(1):29-32

80. Benjamini Y, Hochberg Y. Controlling false discovery rate: a practical approach to multiple testing. J R Stat Soc. 1995:57(1):289-300.

81. Dufresne J, et al. The plasma peptides of ovarian cancer. Clin Proteomics. 2018:15:41.

82. Dufresne J, et al. The proteins cleaved by endogenous tryptic proteases in normal EDTA plasma by C18 collection of peptides for liquid chromatography micro electrospray ionization and tandem mass spectrometry. Clin Proteomics. 2017:14:39.

83. San Segundo-Acosta P, et al. Identification of Alzheimer's disease autoantibodies and their target biomarkers by phage microarrays. J Proteome Res. 2019:18(7):2940-53.

84. Xue M, et al. Up-regulated MCPIP1 in abdominal aortic aneurysm is associated with vascular smooth muscle cell apoptosis and MMPs production. 2019. Biosci Rep. https://doi.org/10.1042/BSR20191252.

85. Morita R, et al. Olfactory receptor family 7 subfamily $C$ member 1 is a novel marker of colon cancer-initiating cells and is a potent target of immunotherapy. Clin Cancer Res. 2016;22(13):3298-309.

86. von Mering $C$ et al. STRING: known and predicted protein-protein associations, integrated and transferred across organisms. Nucleic Acids Res. 2005. 33(Database issue): D433-7.

87. Srikanth $\mathrm{P}$, et al. Convergence of independent DISC1 mutations on impaired neurite growth via decreased UNC5D expression. Transl Psychiatry. 2018;8(1):245.

88. Howard JC, et al. OxLDL receptor chromatography from live human U937 cells identifies SYK(L) that regulates phagocytosis of oxLDL. Anal Biochem. 2016:513:7-20.

89. Morotz GM, et al. Kinesin light chain-1 serine-460 phosphorylation is altered in Alzheimer's disease and regulates axonal transport and processing of the amyloid precursor protein. Acta Neuropathol Commun. 2019:7(1):200.

90. Mielke MM, et al. Serum ceramides increase the risk of Alzheimer disease: the Women's Health and Aging Study II. Neurology. 2012;79(7):633-41.

91. Stoffel W, et al. SMPD3 deficiency perturbs neuronal proteostasis and causes progressive cognitive impairment. Cell Death Dis. 2018;9(5):507.

92. Molinuevo $\mathrm{JL}$, et al. Current state of Alzheimer's fluid biomarkers. Acta Neuropathol. 2018:136(6):821-53.

93. Ohe K, Mayeda A. HMGA1a trapping of U1 snRNP at an authentic $5^{\prime}$ splice site induces aberrant exon skipping in sporadic Alzheimer's disease. Mol Cell Biol. 2010;30(9):2220-8.

94. Harris FM, et al. Carboxyl-terminal-truncated apolipoprotein E4 causes Alzheimer's disease-like neurodegeneration and behavioral deficits in transgenic mice. Proc Natl Acad Sci U S A. 2003;100(19):10966-71.

95. Fridlich $R$, et al. The thioredoxin-like protein rod-derived cone viability factor (RdCVFL) interacts with TAU and inhibits its phosphorylation in the retina. Mol Cell Proteomics. 2009:8(6):1206-18.

96. Paull TT. Mechanisms of ATM Activation. Annu Rev Biochem. 2015;84:711-38.

97. Ait-Ali $\mathrm{N}$, et al. Rod-derived cone viability factor promotes cone survival by stimulating aerobic glycolysis. Cell. 2015;161(4):817-32.

98. Farag AK, Roh EJ. Death-associated protein kinase (DAPK) family modulators: current and future therapeutic outcomes. Med Res Rev. 2019;39(1):349-85.

99. Miller JE, et al. Rare variants in the splicing regulatory elements of EXOC3L4 are associated with brain glucose metabolism in Alzheimer's disease. BMC Med Genomics. 2018;11(Suppl 3):76.

100. Kumagai $A$, et al. Altered actions of memantine and NMDAinduced currents in a new Grid2-deleted mouse line. Genes (Basel). 2014:5(4):1095-114.

101. Arodin $\mathrm{L}$, et al. Alteration of thioredoxin and glutaredoxin in the progression of Alzheimer's disease. J Alzheimers Dis. 2014;39(4):787-97.

102. Rizzo R, et al. KIR2DS2/KIR2DL2/HLA-C1 haplotype is associated with Alzheimer's disease: implication for the role of herpesvirus infections. J Alzheimers Dis. 2019;67(4):1379-89. 
103. Misra MK, Damotte V, Hollenbach JA. The immunogenetics of neurological disease. Immunology. 2018;153(4):399-414.

104. Park YH, et al. Dysregulated Fc gamma receptor-mediated phagocytosis pathway in Alzheimer's disease: network-based gene expression analysis. Neurobiol Aging. 2020;88:24-32.

105. $\mathrm{Ni} \mathrm{H}$, et al. The GWAS risk genes for depression may be actively involved in Alzheimer's disease. J Alzheimers Dis. 2018;64(4):1149-61.

106. Zheng $Y$, et al. Inhibition of EHMT1/2 rescues synaptic and cognitive functions for Alzheimer's disease. Brain. 2019:142(3):787-807.

107. Clemessy $M$, et al. Expression of dual angiogenic/neurogenic growth factors in human primary brain tumors. J Neurooncol. 2012;107(1):29-36.

108. Zhao ML, et al. Optical depolarization of DCX-expressing cells promoted cognitive recovery and maturation of newborn neurons via the Wnt/beta-catenin pathway. J Alzheimers Dis. 2018;63(1):303-18.

109. Ito $\mathrm{S}$, et al. Involvement of insulin-degrading enzyme in insulin- and atrial natriuretic peptide-sensitive internalization of amyloid-beta peptide in mouse brain capillary endothelial cells. J Alzheimers Dis. 2014;38(1):185-200.

110. Zhao Z, Ma L. Regulation of axonal development by natriuretic peptide hormones. Proc Natl Acad Sci U S A. 2009;106(42):18016-21.

111. Burte F, et al. Disturbed mitochondrial dynamics and neurodegenerative disorders. Nat Rev Neurol. 2015;11(1):11-24.

112. Porcelli $\mathrm{S}$, et al. Alzheimer's disease and neurotransmission gene variants: focus on their effects on psychiatric comorbidities and inflammatory parameters. Neuropsychobiology. 2019;78(2):79-85.

113. Jie R, et al. LnCRNA KCNQ1OT1 affects cell proliferation, apoptosis and fibrosis through regulating miR-18b-5p/SORBS2 axis and NF-kB pathway in diabetic nephropathy. Diabetol Metab Syndr. 2020;12:77.

114. Yammine M, et al. Spatial gene's (Tbata) implication in neurite outgrowth and dendrite patterning in hippocampal neurons. Mol Cell Neurosci. 2014;59:1-9.

115. Ng A, et al. IL-1 beta, IL-6, TNF- alpha and CRP in elderly patients with depression or Alzheimer's disease: systematic review and meta-analysis. Sci Rep. 2018;8(1):12050.

116. Jiang H, et al. Genetic deletion of TNFRIl gene enhances the Alzheimerlike pathology in an APP transgenic mouse model via reduction of phosphorylated IkappaBalpha. Hum Mol Genet. 2014;23(18):4906-18.

117. Arena A, et al. Developmental expression and dysregulation of miR-146a and miR-155 in down's syndrome and mouse models of down's syndrome and Alzheimer's disease. Curr Alzheimer Res. 2017;14(12):1305-17.

118. Gal J, et al. Detergent insoluble proteins and inclusion body-like structures immunoreactive for PRKDC/DNA-PK/DNA-PKCS, FTL, NNT, and AIFM1 in the amygdala of cognitively impaired elderly persons. J Neuropathol Exp Neurol. 2018;77(1):21-39.

119. Kang WS, et al. Association of tripartite motif family-like 2 (TRIML2) polymorphisms with late-onset Alzheimer's disease risk in a Korean population. Neurosci Lett. 2016;630:127-31.

120. Wang Y, et al. Deubiquitinating enzymes regulate PARK2-mediated mitophagy. Autophagy. 2015;11(4):595-606.

121. Santos TC, et al. Early golgi abnormalities and neurodegeneration upon loss of presynaptic proteins Munc18-1, Syntaxin-1, or SNAP-25. J Neurosci. 2017;37(17):4525-39.

122. Gunawardena S, Yang G, Goldstein LS. Presenilin controls kinesin-1 and dynein function during APP-vesicle transport in vivo. Hum Mol Genet. 2013;22(19):3828-43.

123. Morris JA, et al. DISC1 (Disrupted-In-Schizophrenia 1) is a centrosomeassociated protein that interacts with MAP1A, MIPT3, ATF $4 / 5$ and NUDEL: regulation and loss of interaction with mutation. Hum Mol Genet. 2003;12(13):1591-608.

124. Shimizu S, et al. DISC1-kendrin interaction is involved in centrosomal microtubule network formation. Biochem Biophys Res Commun. 2008;377(4):1051-6

125. Miyoshi K, et al. DISC1 localizes to the centrosome by binding to kendrin. Biochem Biophys Res Commun. 2004;317(4):1195-9.

126. Bradshaw NJ, Porteous DJ. DISC1-binding proteins in neural development, signalling and schizophrenia. Neuropharmacology. 2012;62(3):1230-41

127. Brandon NJ, et al. Disrupted in Schizophrenia 1 and Nudel form a neurodevelopmentally regulated protein complex: implications for schizophrenia and other major neurological disorders. Mol Cell Neurosci. 2004;25(1):42-55.

128. Meyer KD, Morris JA. Disc1 regulates granule cell migration in the developing hippocampus. Hum Mol Genet. 2009;18(17):3286-97.

129. Mao Y, et al. Disrupted in schizophrenia 1 regulates neuronal progenitor proliferation via modulation of GSK3beta/beta-catenin signaling. Cell. 2009;136(6):1017-31.

130. Kim JY, et al. DISC1 regulates new neuron development in the adult brain via modulation of AKT-mTOR signaling through KIAA1212. Neuron. 2009;63(6):761-73.

131. Enomoto A, et al. Roles of disrupted-in-schizophrenia 1-interacting protein girdin in postnatal development of the dentate gyrus. Neuron. 2009;63(6):774-87.

132. Bobo-Jimenez $\mathrm{V}$, et al. APC/C(Cdh1)-Rock2 pathway controls dendritic integrity and memory. Proc Natl Acad Sci U S A. 2017;114(17):4513-8.

133. Wezyk M, Zekanowski C. Role of BRCA1 in neuronal death in Alzheimer's disease. ACS Chem Neurosci. 2018;9(5):870-2.

134. Yasojima K, et al. Up-regulated production and activation of the complement system in Alzheimer's disease brain. Am J Pathol. 1999;154(3):927-36.

135. Mishra M, Akatsu $\mathrm{H}$, Heese $\mathrm{K}$. The novel protein MANI modulates neurogenesis and neurite-cone growth. J Cell Mol Med. 2011;15(8):1713-25.

136. Liu FF, et al. Regulatory mechanism of microRNA-377 on $\mathrm{CDH} 13$ expression in the cell model of Alzheimer's disease. Eur Rev Med Pharmacol Sci. 2018;22(9):2801-8.

137. Potts RC, et al. CHD5, a brain-specific paralog of Mi2 chromatin remodeling enzymes, regulates expression of neuronal genes. PLoS One. 2011;6(9):e24515

138. Weiss LA, Nieto M. The crux of Cux genes in neuronal function and plasticity. Brain Res. 2019;1705:32-42.

139. Itokazu Y, Yu RK. Amyloid beta-peptide 1-42 modulates the proliferation of mouse neural stem cells: upregulation of fucosyltransferase IX and notch signaling. Mol Neurobiol. 2014;50(1):186-96.

140. Beecham GW, et al. Genome-wide association meta-analysis of neuropathologic features of Alzheimer's disease and related dementias. PLoS Genet. 2014;10(9):e1004606.

141. Liang $X$, et al. Genomic convergence to identify candidate genes for Alzheimer disease on chromosome 10. Hum Mutat. 2009;30(3):463-71.

142. Oroz J, et al. Structure and pro-toxic mechanism of the human Hsp90/ PPlase/Tau complex. Nat Commun. 2018;9(1):4532.

143. $\mathrm{XuXF}$, et al. Elevating Integrin-linked Kinase expression has rescued hippocampal neurogenesis and memory deficits in an $A D$ animal model. Brain Res. 2018;1695:65-77.

144. Hares K, et al. Overexpression of kinesin superfamily motor proteins in Alzheimer's disease. J Alzheimers Dis. 2017;60(4):1511-24.

145. Jin Y, Zheng B. Multitasking: dual leucine zipper-bearing kinases in neuronal development and stress management. Annu Rev Cell Dev Biol. 2019;35:501-21.

146. Ma MW, et al. NADPH oxidase in brain injury and neurodegenerative disorders. Mol Neurodegener. 2017;12(1):7.

147. Alonso-Andres $\mathrm{P}$, et al. Purine-related metabolites and their converting enzymes are altered in frontal, parietal and temporal cortex at early stages of Alzheimer's disease pathology. Brain Pathol. 2018;28(6):933-46.

148. Gusev FE, et al. Epigenetic-genetic chromatin footprinting identifies novel and subject-specific genes active in prefrontal cortex neurons. FASEB J. 2019;33(7):8161-73.

149. Salminen A, Kauppinen A, Kaarniranta K. 2-Oxoglutarate-dependent dioxygenases are sensors of energy metabolism, oxygen availability, and iron homeostasis: potential role in the regulation of aging process. Cell Mol Life Sci. 2015;72(20):3897-914.

150. Zerbinatti $C V$, et al. Oxysterol-binding protein-1 (OSBP1) modulates processing and trafficking of the amyloid precursor protein. Mol Neurodegener. 2008;3:5.

151. Parra-Damas A, Saura CA. Synapse-to-nucleus signaling in neurodegenerative and neuropsychiatric disorders. Biol Psychiatry. 2019:86(2):87-96.

152. Rabal O, et al. Multitarget approach for the treatment of Alzheimer's disease: inhibition of phosphodiesterase 9 (PDE9) and histone deacetylases (HDACs) covering diverse selectivity profiles. ACS Chem Neurosci. 2019;10(9):4076-101. 
153. Tomita S, et al. Interaction of a neuron-specific protein containing PDZ domains with Alzheimer's amyloid precursor protein. J Biol Chem. 1999;274(4):2243-54.

154. Bamburg JR, Bernstein BW. Actin dynamics and cofilin-actin rods in alzheimer disease. Cytoskeleton (Hoboken). 2016;73(9):477-97.

155. Welty S, et al. RAD52 is required for RNA-templated recombination repair in post-mitotic neurons. J Biol Chem. 2018;293(4):1353-62.

156. Canet $\mathrm{G}$, et al. Central role of glucocorticoid receptors in Alzheimer's disease and depression. Front Neurosci. 2018:12:739.

157. Yang Q, et al. correlations between single nucleotide polymorphisms, cognitive dysfunction, and postmortem brain pathology in Alzheimer's disease among Han Chinese. Neurosci Bull. 2019;35(2):193-204.

158. Lovell MA, et al. Alterations in zinc transporter protein-1 (ZnT-1) in the brain of subjects with mild cognitive impairment, early, and late-stage Alzheimer's disease. Neurotox Res. 2005;7(4):265-71.

159. Xu B, et al. Quantitative protein profiling of hippocampus during human aging. Neurobiol Aging. 2016;39:46-56.

160. Lukiw WJ, Rogaev El. Genetics of aggression in Alzheimer's Disease (AD). Front Aging Neurosci. 2017;9:87.

161. Paudel $R$, et al. Neuropathology of Beta-propeller protein associated neurodegeneration (BPAN): a new tauopathy. Acta Neuropathol Commun. 2015:3:39.
162. Chaudhry M, et al. Genetic variation in imprinted genes is associated with risk of late-onset Alzheimer's disease. J Alzheimers Dis. 2015;44(3):989-94.

163. Bis JC, et al. Whole exome sequencing study identifies novel rare and common Alzheimer's-Associated variants involved in immune response and transcriptional regulation. Mol Psychiatry, 2018.

164. Marshall J, et al. Creation of a federated database of blood proteins: a powerful new tool for finding and characterizing biomarkers in serum. Clin Proteomics. 2014;11(1):3.

165. Dufresne J, et al. The plasma peptides of breast versus ovarian cancer. Clin Proteomics. 2019:16:43.

\section{Publisher's Note}

Springer Nature remains neutral with regard to jurisdictional claims in published maps and institutional affiliations.
Ready to submit your research? Choose BMC and benefit from:

- fast, convenient online submission

- thorough peer review by experienced researchers in your field

- rapid publication on acceptance

- support for research data, including large and complex data types

- gold Open Access which fosters wider collaboration and increased citations

- maximum visibility for your research: over $100 \mathrm{M}$ website views per year

At BMC, research is always in progress.

Learn more biomedcentral.com/submissions 